\title{
Contrôle de la qualité des eaux domestiques dans le village Babessi au Nord-Ouest Cameroun
}

\author{
Njoyim Estella Buleng TAMUNGANG ${ }^{*}$, Nchofua Festus BIOSENGAZEH, \\ Mofor Nelson ALAKEH et Djoko Yves TAMEU \\ Laboratory of Noxious Chemistry and Environmental Engineering (LANOCHEE), Department of Chemistry, \\ Faculty of Science, University of Dschang, Dschang, Cameroon. \\ *Corresponding author; E-mail: bulengyim@yahoo.com
}

\section{RÉSUMÉ}

L'étude porte sur l'évaluation de la qualité des eaux domestiques et leurs effets sur la santé de la population dans le village Babessi, Nord-Ouest Cameroun, en se basant sur les normes établies par l'Organisation Mondiale de la Santé. Dans les zones rurales du Cameroun où les réseaux publiques de distribution d'eau sont inexistants, la population consomme les eaux d'origine diverses de caractéristiques inconnues. Trente échantillons d'eau d'un puits et de quatre rivières des quartiers Mbezoh, Ntuoncho, Ndokeba, Chui et Chumanda ont été analysés au mois de janvier et aout 2015 pour certains paramètres physiques, chimiques et bactériologiques, en utilisant les méthodes standard. Les résultats ont indiqué que ces eaux étaient faiblement acides en août ( $\mathrm{pH}$ entre 5,5 et 6,2), faiblement minéralisées (conductivité électrique entre 28,2 et $280 \mu \mathrm{S} / \mathrm{cm}$ ) et fortement turbides (turbidité entre 9,9 et $236 \mathrm{UNT}$ ). Tous les ions majeurs répondaient aux normes. Néanmoins, le chrome et fer étaient fortement concentrés dans presque tous les échantillons au mois de janvier $(0,14$ à $0,34 \mathrm{mg} / \mathrm{l}$ et de 0,26 à $3,26 \mathrm{mg} / \mathrm{l}$ respectivement $)$ de même que le Plomb en août dans le puits de Mbezoh $(0,08 \mathrm{mg} / \mathrm{l})$ et la rivière de Ndokebah $(0,38 \mathrm{mg} / \mathrm{l})$. Sur l'aspect bactériologique, les eaux étaient fortement polluées. Tous les échantillons contenaient les formes fécales d'entérobactères, de Escherichia coli, de streptocoque, de salmonelle, de shigelle et de staphylocoque. La mauvaise qualité de ces eaux était justifiée par la prédominance des infections d'origine hydrique dans ce village notamment la thyphoïde, la diarrhée et la dysenterie. Les analyses statistiques ont révélé des différences significatives dans la variation de certains paramètres ainsi que de fortes corrélations entre ces derniers. La forte présence des bactéries et la non-conformité de certains paramètres pouvaient être attribuées aux activités agricoles, l'élevage, le mauvais entretien et certains phénomènes naturels. L'urgente attention accordée à l'entretien des points d'eau et un traitement adéquat de l'eau à domicile avant consommation sont nécessaires.

(C) 2016 International Formulae Group. All rights reserved.

Mots clés : Qualité de l'eau, pollution, analyse, bactéries, infections, risque sanitaire.

\section{Quality control of domestic water in Babessi village in North-West Cameroon}

\begin{abstract}
This study is related to the evaluation of the quality of domestic water and it effects on public health in the Babessi village, North-Western Cameroun with respect to World Health Organization standards. In the rural zones of Cameroun where the public network of water distribution is non-existent, the population consumes water from various origins of unknown characteristics. Thirty samples of water from a well and four
\end{abstract}


rivers of the districts: Mbezoh, Ntuoncho, Ndokeba, Chui and Chumanda were analyzed in January and August 2015 for certain physical, chemical and bacteriological parameters using standard methods. The results indicated that this water was slightly acidic in August ( $\mathrm{pH}$ between 5.5 and 6.2), slightly mineral-bearing (electric conductivity between 28.2 and $280 \mu \mathrm{S} / \mathrm{cm}$ ) and strongly turbid (turbidity between 9.9 and $236 \mathrm{UNT}$ ). All the major ions met WHO specifications. Nevertheless, chromium and iron were strongly concentrated in almost all the samples in January ( 0.14 to $0.34 \mathrm{mg} / \mathrm{l}$ and from 0.26 to $3.26 \mathrm{mg} / \mathrm{l}$ respectively) just as Lead in August in the well at Mbezoh $(0.08 \mathrm{mg} / \mathrm{l})$ and the river at Ndokebah $(0.38 \mathrm{mg} / \mathrm{l})$. As far as the bacteriological aspect is concerned, all water samples were strongly polluted. All the samples contained the fecal forms of enterobacteria, Escherichia coli, Streptococcus, Salmonella, Shigella and Staphilococcus. The bad quality of this water was justified by the prevalence of infections of typhoid, diarrhoea and dysentery in this village. Statistical analyses revealed significant differences in the variation of certain parameters as well as strong correlations between the latter. The strong presence of the bacteria and the nonconformity of certain parameters could be attributed to the agricultural activities, breeding, bad maintenance and certain natural phenomena. Urgent attention to the maintenance of the water resources in this locality and an adequate treatment of water in residences before consumption is necessary.

(C) 2016 International Formulae Group. All rights reserved.

Keywords: Water quality, pollution, analyses, bacteria, infections, medical risk.

\section{INTRODUCTION}

L'accès à une eau de boisson saine est une condition indispensable à la santé, un droit humain élémentaire et une composante clé des politiques efficaces de protection sanitaire. L'importance de l'eau, de l'assainissement et de l'hygiène pour la santé et le développement transparaît dans les conclusions d'une série de forums politiques internationaux, comprenant des conférences axées sur la santé telles que la Conférence internationale sur les soins de santé primaires, réunie à Alma-Ata, Kazakhstan (ex-Union soviétique) en 1978, ainsi que des conférences axées sur l'eau comme la Conférence mondiale sur l'eau de Mar del Plata (Argentine), qui ont ouvert la voie à la Décennie de l'eau de boisson et de l'assainissement (1981-1990), aux objectifs du Millénaire pour le développement, adoptés par l'Assemblée générale des Nations Unies (ONU) en 2000 et aux résultats du Sommet mondial de Johannesburg pour le développement durable en 2002. Plus récemment, l'Assemblée générale des Nations Unies a déclaré la période allant de 2005 à 2015 Décennie internationale d'action « L'eau source de vie » (OMS, 2004).
Le programme commun OMSUNICEF de suivi de l'approvisionnement en eau et de l'assainissement (JMP) rapporte des gains impressionnants faits pendant les deux dernières décennies avec 2,6 milliards de personnes accédant à une source améliorée d'eau potable et 2,1 milliards à un service amélioré d'hygiène. Cependant, beaucoup reste à faire car 663 millions de personnes restent sans source améliorée d'eau potable avec 319 millions en Afrique subsaharienne, et 2,4 milliards sans une installation d'assainissement améliorée et parmi les personnes qui n'ont toujours pas accès à ces points d'eau, 8 sur 10 vivent en zone rurale (OMS et UNICEF, 2015). L'eau constitue les deux tiers des liquides de l'organisme chez l'homme et joue un rôle important. Elle assure l'hydratation des cellules du corps, ainsi qu'un rôle de véhicule de certaines substances nutritives (N'diaye, 2008). Toutefois, de par sa qualité, elle peut nuire à la santé de l'homme (OMS, 2004). L'eau insalubre est à l'origine de plusieurs maladies hydriques, surtout dans les pays en voie de développements (Nanfack et al., 2014). Et, parmi les facteurs responsables de ces 
infections, les bactéries tiennent une place non négligeable (Hounsou et al., 2010). La mauvaise qualité de l'eau peut être induite par des activités anthropiques, notamment la pollution, ainsi que le mauvais assainissement et l'hygiène des sources d'eaux (Torkil, 2004 ; Nanfack et al., 2014). A cause de la faible disponibilité de l'eau potable dans les zones urbaines, périurbaines et rurales dans certains pays africains, les populations sont contraintes de s'approvisionner en eau dont la potabilité est très douteuse. Le Cameroun est doté de nombreuses ressources d'eau (Wirmvem et al., 2013a) mais l'accès à l'eau potable reste un problème. Plusieurs auteurs ont traité de cette problématique (Djuikom et al., 2011 ; Temgoua, 2011 ; Sorlini et al., 2013 ; Niba et Nchang, 2013; Wirmvem et al., 2013; Nanfack et al., 2014). Moins de $40 \%$ des habitants en zones rurales et $65 \%$ dans les villes moyennes ont accès à l'eau de boisson saine (Fonteh, 2003 ; Nanfack et al., 2014). Avec l'augmentation de la population, la demande élevée en eau, particulièrement dans les zones rurales est comblée par les cours d'eau, les sources et les puits dont la qualité est généralement inconnue. Les cours d'eau et les puits sont les principales sources d'approvisionnement en eau destinée aux usages domestiques dans le village Babessi. L'acceptabilité d'un cours d'eau ou d'un puits à la consommation dans cette localité est généralement basée sur l'appréciation de certaines caractéristiques organoleptiques et physiques (odeur et l'apparence). Or une eau de bonne qualité n'est pas uniquement limpide, inodore et agréable à boire, mais elle est aussi celle qui répond aux critères physicochimiques et bactériologiques bien définis, pouvant être consommée sans aucun risque notable pour la santé d'une personne qui la consommerait sur toute la durée de sa vie, compte tenu des variations de sensibilité éventuelles entre les différents stades de la vie (OMS, 2004). La majorité des puits sont souvent creusés de façon artisanale, peu profonds, non protégés et situés à proximité des lattrines, ce qui émet des doutes sur la qualité de l'eau à cause des infiltrations possibles d'eau sale, d'urine ou d'excréments d'animaux (Labas et Vuik, 2010 ; Nanfack et al., 2014). Quant aux cours d'eau, ils coulent à l'air libre, sont proches des exploitations agricoles et sont souvent partagés avec les bœufs en transhumance en saison sèche et exposés à des inondations en saison pluvieuse. La consommation de ces eaux exposerait la population à des maladies d'origine microbienne telles que la fièvre typhoïde, la dysenterie bacillaire, la diarrhée et les gastroentérites, les hépatites $\mathrm{A}$ et $\mathrm{E}$, et la dysenterie amibienne (WHO, 2011). Le présent travail vise à évaluer la qualité bactériologique, certains paramètres physico-chimiques et l'impact sanitaire des eaux à usages domestiques dans la localité de Babessi.

\section{MATERIEL ET METHODES}

Présentation de la zone d'étude

Les eaux analysées ont été prélevées dans le village Babessi, chef-lieu de son arrondissement. Ayant une population de 19 000 habitants (CAMAAY, 2015), ce village est situé entre la latitude et la longitude 6.0167 $\mathrm{N}$ et 10.5667 E. L'activité principale des habitants reste l'agriculture, l'élevage et le petit commerce. Le village est localisé dans la plaine de Ndop et il a un climat caractérisé par deux saisons; une courte saison sèche qui va de novembre à février et une longue saison de pluie qui va de mars à octobre. La température maximale annuelle varie entre $27,2{ }^{\circ} \mathrm{C}$ et 33,6 ${ }^{\circ} \mathrm{C}$ alors que la température minimale annuelle varie entre $7,8{ }^{\circ} \mathrm{C}$ et $15,9{ }^{\circ} \mathrm{C}$. La pluviométrie varie entre $1270 \mathrm{~mm}$ et $1778 \mathrm{~mm}$ d'eau par an. L'hydrographie de ce village est 
caractérisée par l'existence des petits cours d'eau, des forages et des ruisseaux. Les sols sont principalement basaltiques, trachytiques et/ou granitiques favorables pour l'agriculture et le pâturage. La végétation est principalement faite de la savane avec des plantes telles que les palmiers à huile, les raphias, les eucalyptus et kolas ayant des fins économiques (CVUC, 2014).

\section{Echantillonage}

L'échantillonnage et la conservation des échantillons sont très délicats dans l'analyse de l'eau car ils conditionnent les résultats. Les eaux de quatre rivières et d'un puits ont été retenues pour les analyses. Ces points d'eau sont repartis dans cinq quartiers dont Mbezoh, Ntuoncho, Ndokebah, Chui et Chumanda. 30 échantillons d'eau ont été prélevés aux mois de janvier et août 2015 (correspondant à la saison sèche et la saison pluvieuse respectivement) plus précisément le 12 janvier et le 03 août très tôt le matin. La sélection de ces points d'eau à analyser a été basée sur la fréquence d'utilisation, c'est-àdire les plus utilisées et la proximité de ces points d'eau avec diverses sources de pollution telles que les latrines et les exploitations agricoles. Les échantillons ont été prélévés dans des bouteilles en polyéthylène de contenance 0,35 litre. Chaque échantillon a été identifié à l'aide d'étiquettes et ces échantillons étaient ensuite conservés dans une glacière remplie de glace pour maintenir la température à moins de $4{ }^{\circ} \mathrm{C}$ (Rodier et al., 1984). Les échantillons destinés au dosage des métaux lourds étaient conservés à l'acide nitrique concentré. L'ensemble a été transporté au le Laboratoire d'Analyse des Sols et de Chimie de l'Environnement et le Laboratoire de la Physiologie Animale et Microbiologie de la Faculté d'Agronomie et des Sciences Agricoles de l'Université de
Dschang où ont été effectuées respectivement les analyses physico-chimiques et bactériologiques.

\section{Analyses physico-chimiques}

Le $\mathrm{pH}$, la température et la conductivité ont été déterminés in situ à l'aide d'un multimètre HANNA H19811-5 pH/T/EC.

La mesure de la turbidité a été effectuée en utilisant un turbidimètre modèle DR2010.

$\mathrm{Au}$ laboratoire, les ions $\mathrm{HCO}_{3}^{-}, \mathrm{NH}_{4}^{+}, \mathrm{NO}_{3}^{-}$et $\mathrm{Cl}^{-}$ont été dosés par titration; l'ion $\mathrm{SO}_{4}^{2-}$ a été dosé par la méthode gravimétrique; l'ion $\mathrm{PO}_{4}^{3-}$ a été dosé par spectrométrie ultraviolet; les ions $\mathrm{Na}^{+}$et $\mathbf{K}^{+}$ont été dosés par spectrophotométrie d'émission de flamme ; les ions $\mathrm{Ca}^{2+}, \mathrm{Mg}^{2+}, \mathrm{Zn}^{2+}, \mathrm{Cr}^{3+}, \mathrm{Pb}^{2+}$, $\mathrm{Fe}^{2+}$ et $\mathrm{Fe}^{3+}$ ont été dosés par spectrophotométrie à absorption atomique (SAA).

\section{Analyses bactériologiques}

Deux techniques à savoir, la technique de dénombrement des germes sur milieu liquide (la technique du nombre le plus probable) et sur milieu solide (la technique standard ou count plate) ont été utilisées pour déterminer les différents pathogènes présents dans les échantillons.

\section{Technique du nombre le plus probable}

Cette technique a consisté premièrement à stériliser la verrerie à $160{ }^{\circ} \mathrm{C}$ pendant 2 heures. Le bouillon de MacConkey a ensuite été préparé, distribué dans les bouteilles stérilisées et introduit dans un autoclave à $120{ }^{\circ} \mathrm{C}$ pendant 15 minutes comme indiqué par l'OMS (2006). A l'aide des seringues stérilisées, $50 \mathrm{ml}$ et $10 \mathrm{ml}$ d'échantillon d'eau ont été introduits 
respectivement dans les bouteilles contenant $100 \mathrm{ml}$ et $20 \mathrm{ml}$ de bouillons de culture, tandis que $1 \mathrm{ml}$ d'eau a été introduit dans les bouteilles contenant $5 \mathrm{ml}$ de bouillons de culture. Le contenu de chaque bouteille fermée, a été entièrement agité. Ensuite, ces bouteilles ont été placées dans un bain-marie pour incubation à $44{ }^{\circ} \mathrm{C}$ pendant 24 heures. Après incubation, les bouteilles ont été examinées et celles qui ont produit le gaz indiquant la présence des bactéries ont été comptées.

\section{Technique standard (count plate)}

Les milieux de culture spécifiques à chaque bactérie ont été mesurés à l'aide d'une balance et introduits dans des béchers stériles contenant chacun $300 \mathrm{ml}$ d'eau distillée. Ces mélanges ont aussitôt été stérilisés à $120^{\circ} \mathrm{C}$ pendant 15 minutes. Après refroidissement (environ $45^{\circ} \mathrm{C}$ ), les milieux de culture ont été introduits dans les boîtes de pétri contenant chacune $1 \mathrm{ml}$ d'échantillon d'eau et mélangés jusqu'à solidification de la gélose. Le nombre de colonies des différents pathogènes a enfin été compté à l'œil nu après avoir retourné et incubé les boîtes de pétri à $44{ }^{\circ} \mathrm{C}$ pendant 24 heures.

\section{Analyses statistiques}

Le test de Student (t-test) a été employé pour comparer les moyennes des différents paramètres en janvier et en août. La corrélation de Pearson a été utilisée pour étudier les relations entre les différents paramètres pendant les périodes d'analyses. Les analyses statistiques ont été effectuées en utilisant SPSS version 19.0.

\section{RESULTATS}

\section{Paramètres physiques}

Les paramètres physiques déterminés sont la température, le potentiel d'hydrogène, la conductivité électrique et la turbidité. Les résultats sont consignés dans le Tableau1.

La température des points d'eau variait entre 20 et $20,7^{\circ} \mathrm{C}$ au mois de janvier et entre 21,7 et $22,1^{\circ} \mathrm{C}$ en août. Le pH était compris entre 6,3 et 7 en janvier et entre 5,5 et 6,2 en août. Ces valeurs de $\mathrm{pH}$ indiquaient qu'au mois de janvier, seul le puits du quartier Mbezoh était faiblement acide alors qu'en août, tous les points d'eau étaient faiblement acides comparativement aux normes de l'OMS (6,5-9,5). L'augmentation de la température et la diminution du $\mathrm{pH}$ en janvier et en août étaient significatives du point de vue statistique $(p<0,05)$. La conductivité électrique variait de 44 à $152,2 \mu \mathrm{S} / \mathrm{cm}$ en janvier et de 28,2 à $280 \mu \mathrm{S} / \mathrm{cm}$ au mois d'août. La turbidité quant à elle, variait entre 9,9 et 20,3 UNT au mois de janvier et entre 33 et 236 UNT en août, avec une augmentation considérable en ce mois $(\mathrm{p}<0,05)$.

\section{Paramètres chimiques}

Les analyses étaient axées sur les ions majeurs (calcium, magnésium, sodium potassium, chlorure, sulfate, nitrate et bicarbonate), quelques nutriments (phospate et l'ion ammonium) et quelques métaux lourds ( Zinc, Chrome, Plomb et Fer). Les résultats sont consignés dans les Tableaux 2 et 3.

$\mathrm{Ca}^{2+}$ était en traces au mois de janvier et variait de 31 à $55,33 \mathrm{mg} / \mathrm{l}$ au mois d'août sans aucune différence significative ( $>0,05) . \mathrm{Mg}^{2+}$ avait une teneur comprise entre 0,44 et $0,81 \mathrm{mg} / \mathrm{l}$ en janvier et en août il $\mathrm{y}$ avait une augmentation significative en concentration $(\mathrm{p}<0,05)$ qui variait entre 4,02 et $4,04 \mathrm{mg} / \mathrm{l}$. La teneur en $\mathrm{Na}^{+}$variait entre 0,03 et $0,06 \mathrm{mg} / 1$ en janvier et entre 1,02 et $6,08 \mathrm{mg} / \mathrm{l}$ en août. $K^{+}$avait une teneur comprise entre 0,11 et $0,26 \mathrm{mg} / \mathrm{l}$ en Janvier et variait significativement $(p<0,05)$ entre 11,03 
et $11,90 \mathrm{mg} / \mathrm{l}$ en août (Tableau 2). $\mathbf{C l}^{-}$était non détectable dans tous les autres points d'eau à l'exception du puits du quartier Mbezoh qui affichait une teneur de $88,78 \mathrm{mg} / 1$ en janvier et de 3,25 mg/l au mois d'août. La concentration en $\mathrm{SO}_{4}^{2-}$ variait de 0,13 à 0,19 $\mathrm{mg} / \mathrm{l}$ en janvier et de 1,8 à $4,10 \mathrm{mg} / \mathrm{l}$ en août. $\mathrm{NO}_{3}^{-}$au mois de janvier oscillait entre 0,056 et $0,168 \mathrm{mg} / \mathrm{l}$ et entre 0,28 et $3,46 \mathrm{mg} / \mathrm{l}$ au mois d'août. $\mathrm{HCO}_{3}^{-}$variait entre 48,8 et $134,2 \mathrm{mg} / \mathrm{l}$ au mois de janvier et entre 24,4 et $109,8 \mathrm{mg} / \mathrm{l}$ au mois d'août. Les teneurs en $\mathrm{PO}_{4}^{3-}$ variant entre 3,41 et $9,42 \mathrm{mg} / \mathrm{l}$ au mois de janvier et une valeur constante de 0,001 $\mathrm{mg} / \mathrm{l}$ dans tous les échantillons en août ont été enregistrées. Les concentrations en $\mathrm{NH}_{\underline{4}}^{+}$dans les eaux étudiées variaient entre 0.028 et $0,252 \mathrm{mg} / \mathrm{l}$ au mois de janvier et entre 0,84 et $4,48 \mathrm{mg} / \mathrm{l}$ au mois d'août (Tableau 2). Les différences significatives ont également été notées dans la variation de $\mathrm{SO}_{4}^{2-} \mathrm{NO}_{3}^{-}, \mathrm{PO}_{4}^{3-}$ et $\mathrm{NH}_{4}^{+}(\mathrm{p}<0,05)$.

Les résultats de l'analyse des métaux lourds présentés dans le Tableau 3 indiquent que le plomb était en traces dans tous les échantillons, sauf dans le puits du quartier Mbezoh et la rivière du quartier Ndokebah avec des teneurs de $0,08 \mathrm{mg} / 1$ et $0,38 \mathrm{mg} / \mathrm{l}$ respectivement au mois d'août. Les teneurs en $\mathrm{Cr}^{3+}$ enregistrées lors de l'étude étaient de l'ordre de 0,14 à $0,32 \mathrm{mg} / \mathrm{l}$ en janvier et en août, seule la rivière du quartier Ndokebah avait une teneur de $0,55 \mathrm{mg} / 1$, les autres points d'eau n'ayant que des traces. Au mois de janvier, le fer était en traces dans le puits et variait de 0,26 à 3,96 mg/l dans le reste des échantillons et en août, en dehors de la rivière du quartier Ntuoncho qui avait une teneur de $0,07 \mathrm{mg} / \mathrm{l}$ et la rivière du quartier Chui avec une teneur de $0,51 \mathrm{mg} / \mathrm{l}$, le fer était également en traces dans tous les autres échantillons. Aucune différence significative n'a été observée dans la variation des concentrations en plomb, chrome et fer ( $p>0,05)$. Les teneurs en $\mathrm{Zn}^{2+}$ relevées pendant l'étude variaient de 0,83 à $2,78 \mathrm{mg} / \mathrm{l}$ en janvier et de 0,22 à 0,54 $\mathrm{mg} / \mathrm{l}$ en août avec une différence significative $(\mathrm{p}<0,05)$.

\section{Paramètres bactériologiques}

Les résultats des analyses bactériologiques ont révélé que la totalité des points d'eau échantillonés était contaminée. Le taux de colonisation des points d'eau par les coliformes fécaux variait en moyenne entre 5/100 et 90/100 ml d'eau au mois de janvier et entre 14/100 et 90/100 ml d'eau au mois d'août. Ces résultats montrent qu'en janvier, le puits du quartier Mbezoh et la rivière $\mathrm{du}$ quartier Ndokebah étaient acceptables (B), la rivière de Ntuoncho et le forage était impropre à la consommation (C) et les rivières de Chui et Chumanda présentent une pollution énorme (D). Par contre, au mois d'août, aucun des points d'eau n'était acceptable. Les rivières de Ntuoncho, Chui et Chumanda étaient tous impropres à la consommation. Le puits et la rivière de Ndokebah pour autant acceptables en janvier étaient énormement pollués (Tableau 4).

L'analyse approfondie des échantillons a permis d'isoler certaines bactéries pathogènes telles que les Enterobacterères, les Escherichia coli, les Streptocoques, les Salmonelles, les Shigelles et les Staphylocoques. Le taux de colonisation des différents points d'eau variait de 150 à 400 UFC/100 ml en janvier et de 250 à 400 UFC/100 ml en août pour les enterobatères; de 50 à $150 \mathrm{UFC} / 100 \mathrm{ml}$ aux mois de janvier et août pour E.coli ; 200 à $350 \mathrm{UFC} / 100 \mathrm{ml}$ en janvier et de 150 à $350 \mathrm{UFC} / 100 \mathrm{ml}$ en août pour les Streptocoques ; 15 à 150 UFC/100 ml 
en janvier et de 50 à 150 UFC/100 ml en août pour les salmonelles; 0 à $10 \mathrm{UFC} / 100 \mathrm{ml}$ en janvier et de 75 à $150 \mathrm{UFC} / 100 \mathrm{ml}$ en août pour les shigelles et en fin de 0 à $22 \mathrm{UFC} / 100$ $\mathrm{ml}$ en janvier et de 0 à $50 \mathrm{UFC} / 100 \mathrm{ml}$ en août pour les staphylocoques (Tableau 5).

Tableau 6 présente les coefficients de corrélation de peason (r) entre différents paramètres aux mois de janvier et août. Plus $r$ est proche de \pm 1 , plus forte est la corrélation. Ainsi, les fortes corrélations négatives ont été observées particulièrement en août entre le $\mathrm{pH}$ et les ions nitrates et entre $\mathrm{pH}$ et les ions phosphates ( $\mathrm{r}$ très proche de -1 ). Par contre, les corrélations entre: $\mathrm{CE}$ et $\mathrm{HCO}_{3}^{-}, \mathrm{CE}$ et $\mathrm{Mg}^{2+}$, Tu et $\mathrm{PO}_{4}^{3-}, \mathrm{HCO}_{3}^{-}$et $\mathrm{Mg}^{2+}, \mathrm{Cl}^{-}$ et $\mathrm{K}^{+}, \mathrm{Zn}^{2+}$ et $\mathrm{Fe}$ au mois de janvier et EC et $\mathrm{NO}_{3}^{-}$, EC et $\mathrm{Cl}^{-}, \mathrm{Mg}^{2+}$ et $\mathrm{Na}^{+}, \mathrm{Mg}^{2+}$ et $\mathrm{Pb}^{2+}, \mathrm{Mg}^{2+}$ et $\mathrm{Zn}^{2+}, \mathrm{Mg}^{2+}$ et $\mathrm{Cr}^{3+}$, $\mathrm{Pb}^{2+}$ et $\mathrm{Zn}^{2+}, \mathrm{Pb}^{2+}$ et $\mathrm{Cr}^{3+}$, E.coli et Strep, E.coli et Enter étaient positives ( $r$ très proche de 1).

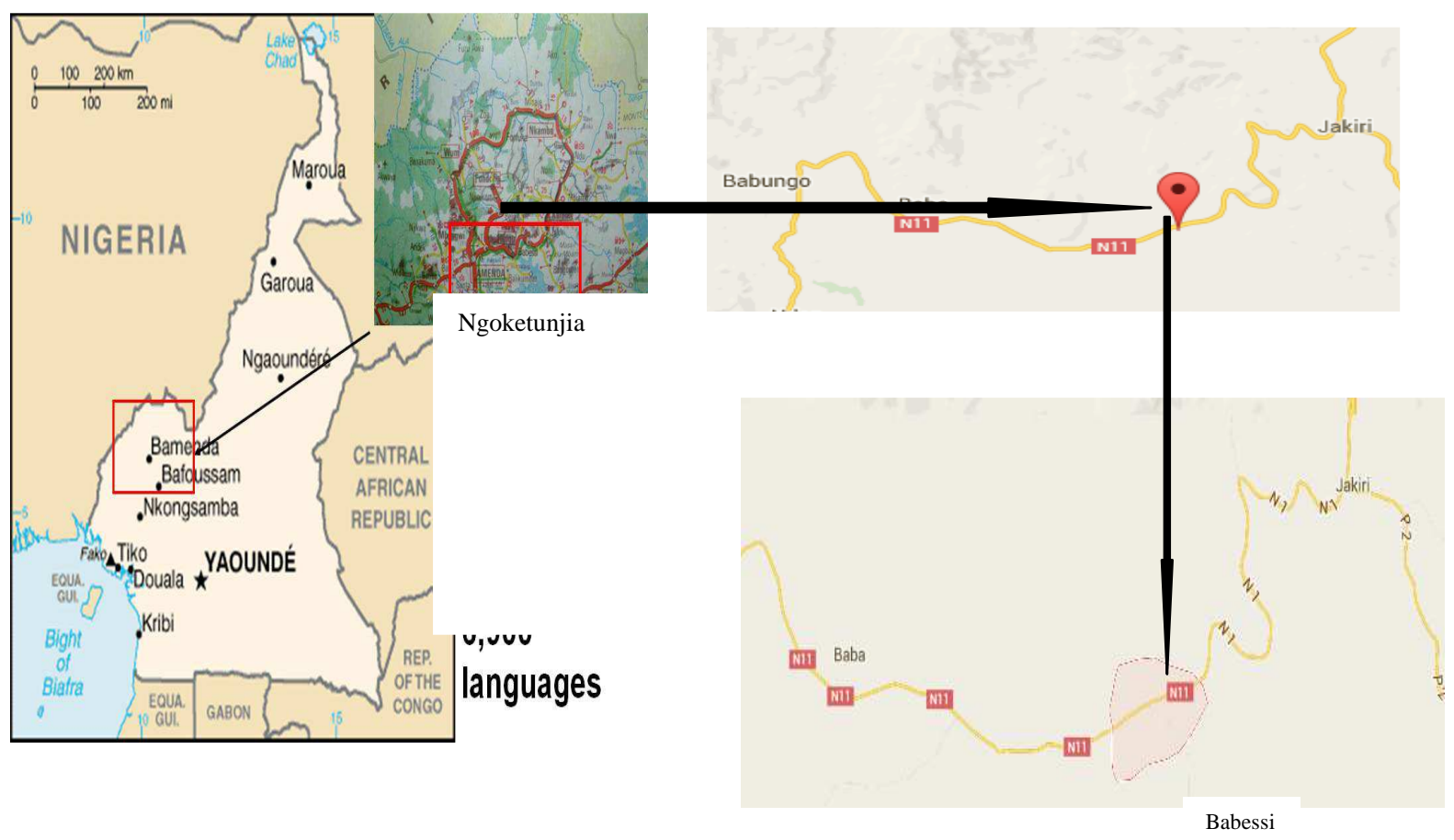

Figure 1 : Localisation géographique de Babessi. 


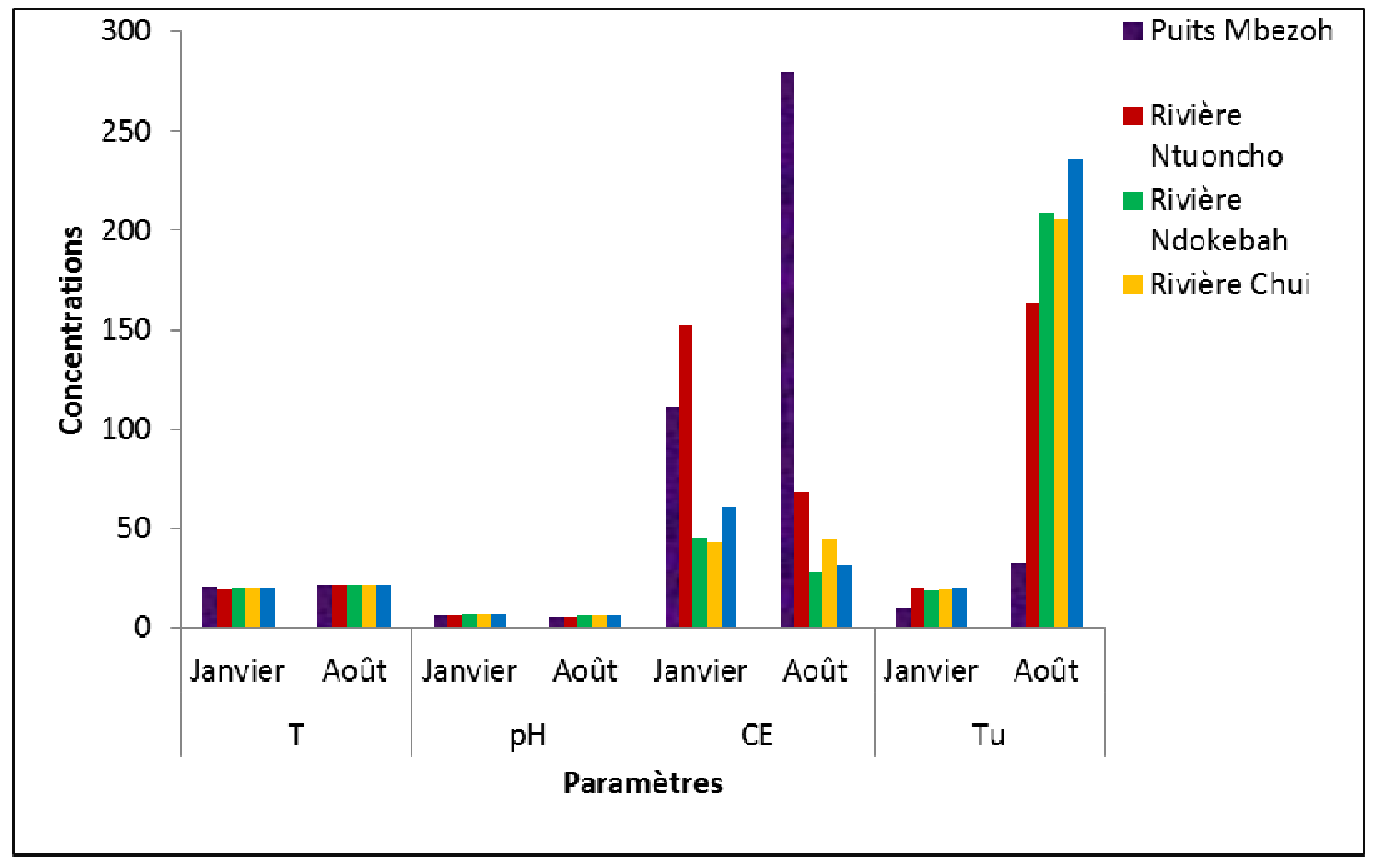

Figure 2 : Variation des paramètres physiques.

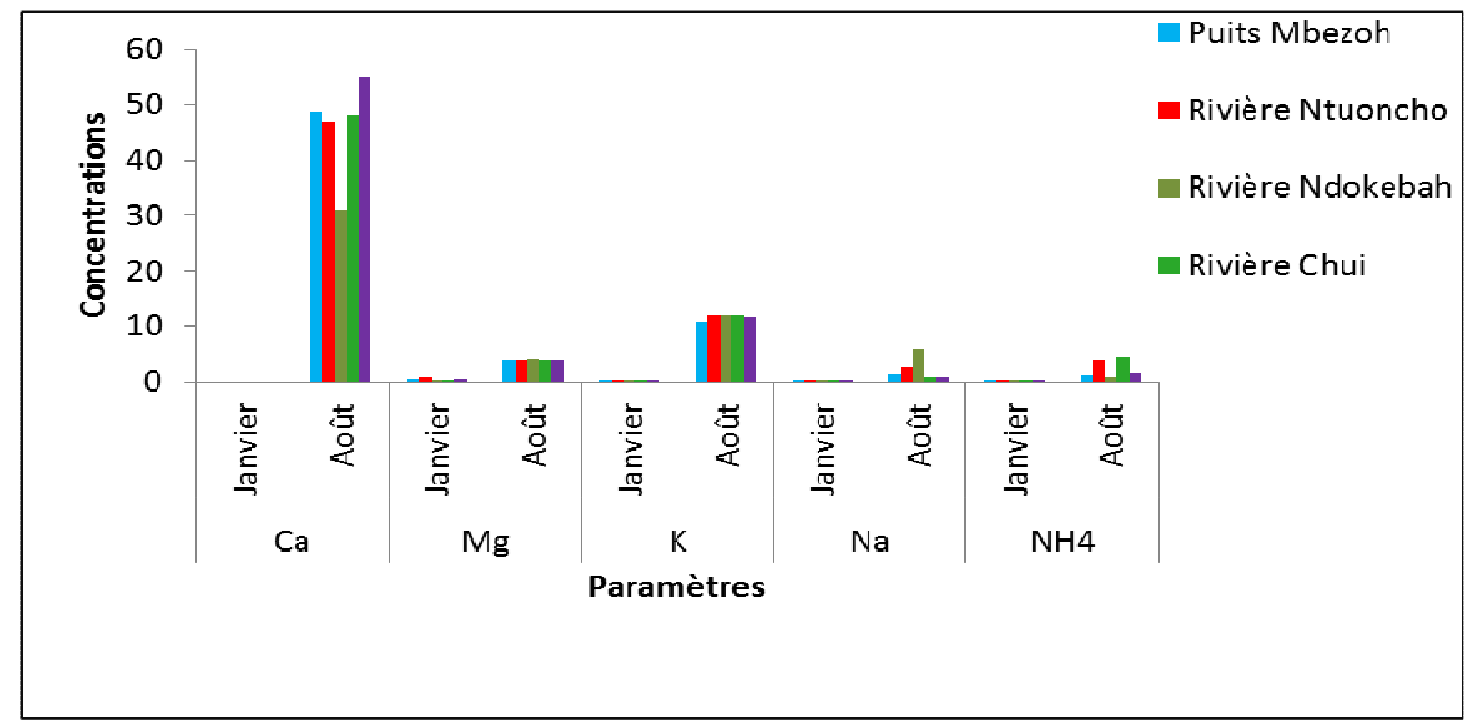

Figure 3 : Variation des concentrations en Cations. 


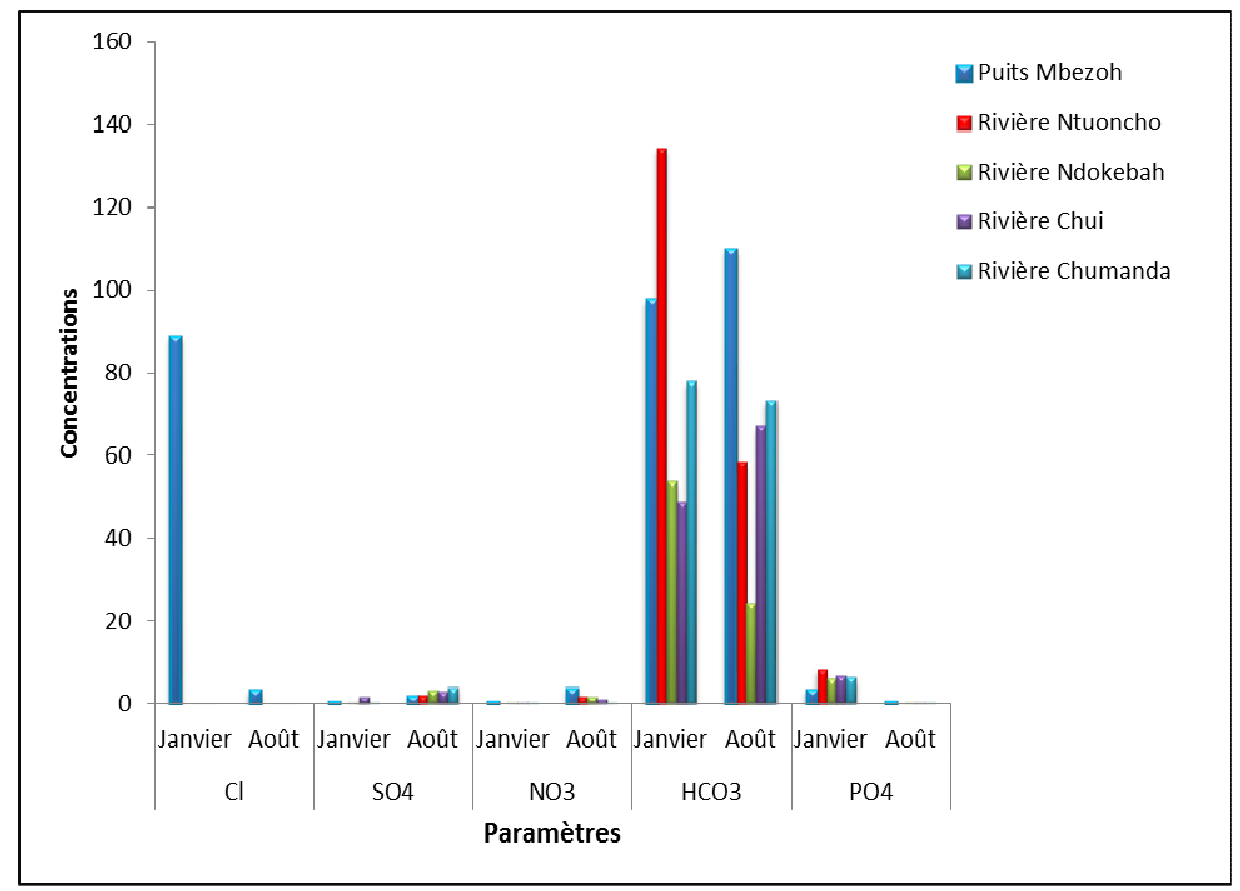

Figure 4 : Variation des concentrations en anions.

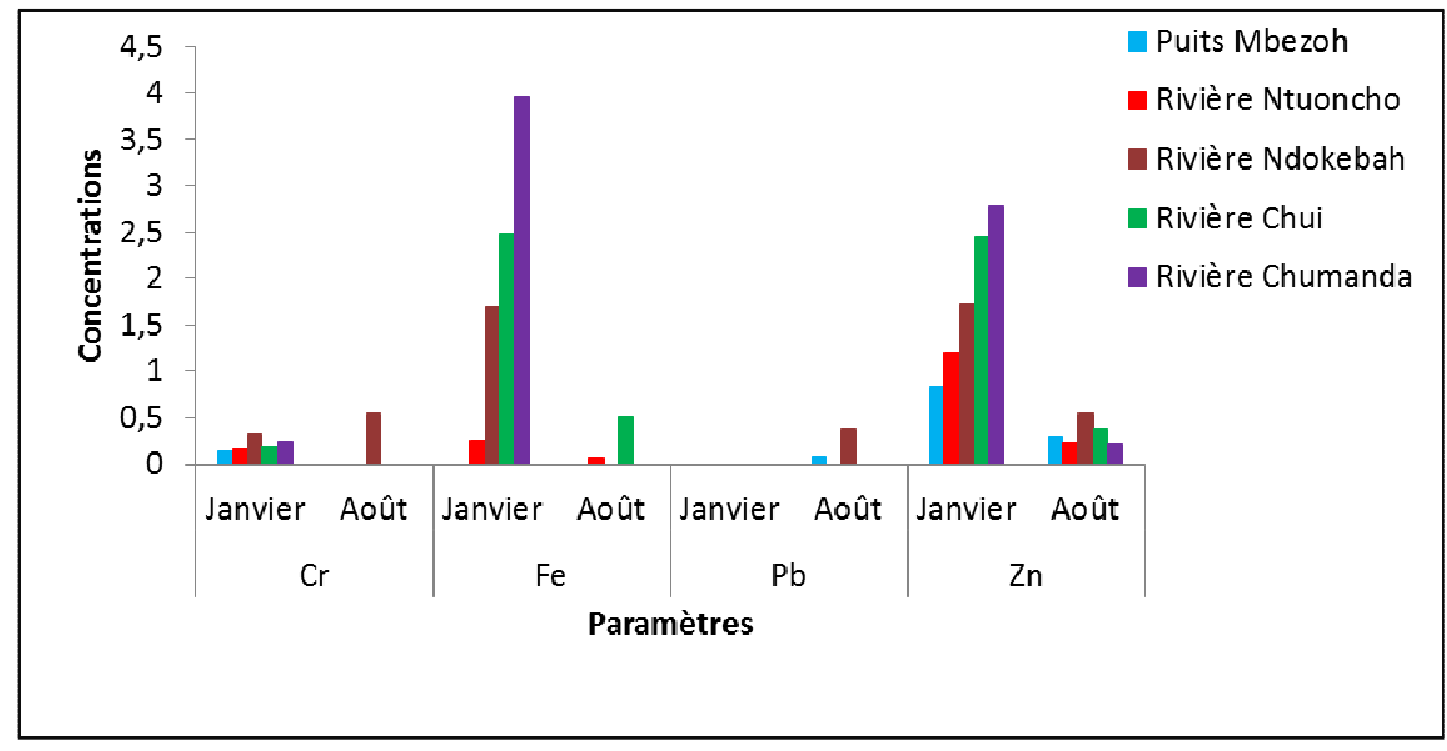

Figure 5 : Variation des concentrations en métaux 


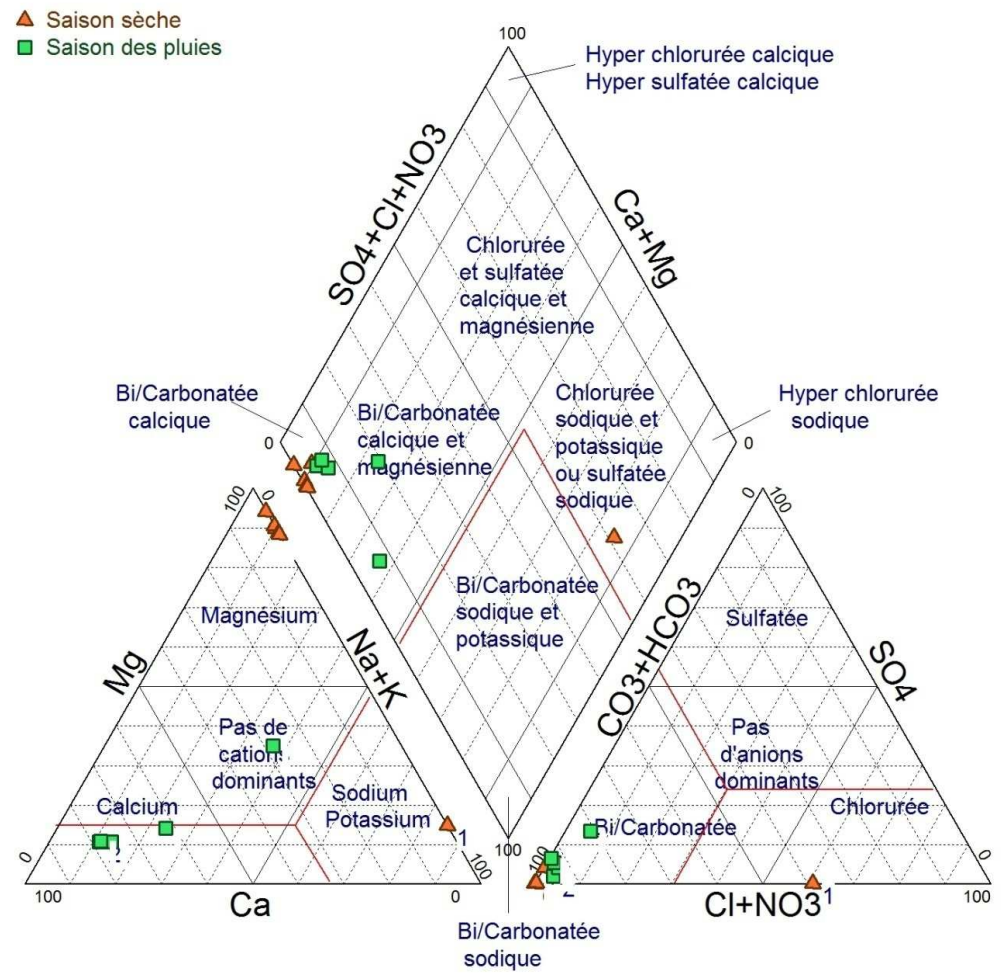

Figure 6 : Diagramme trilinear de Piper des cations et anions dans les échantillons.

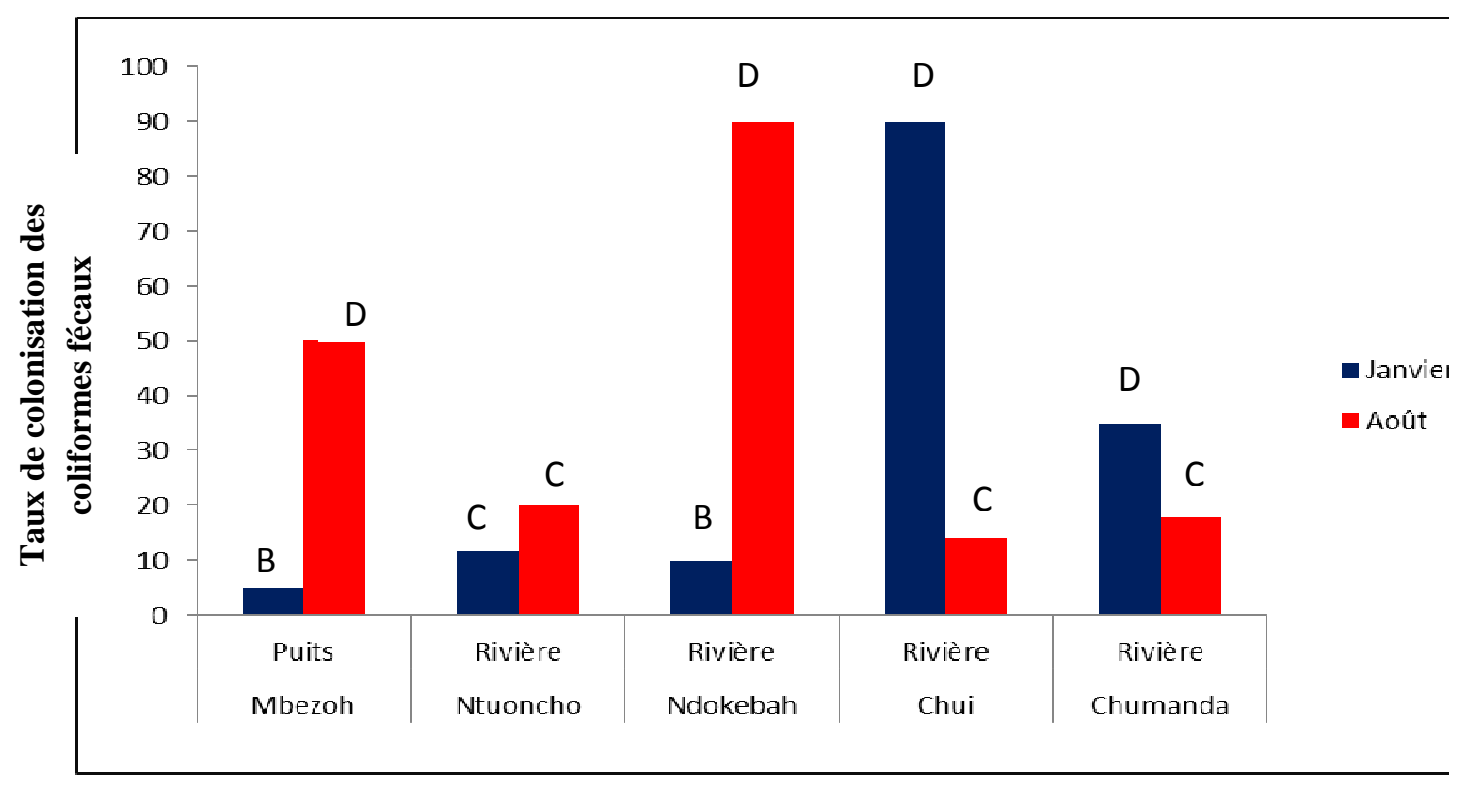

Figure 7 : Classement des points d'eau en fonction du taux de colonisation des coliformes fécaux. $\mathrm{A}=$ Excellent $; \mathrm{B}=$ Acceptable $; \mathrm{C}=$ Impropre à la consommation ; D =Pollution énorme 


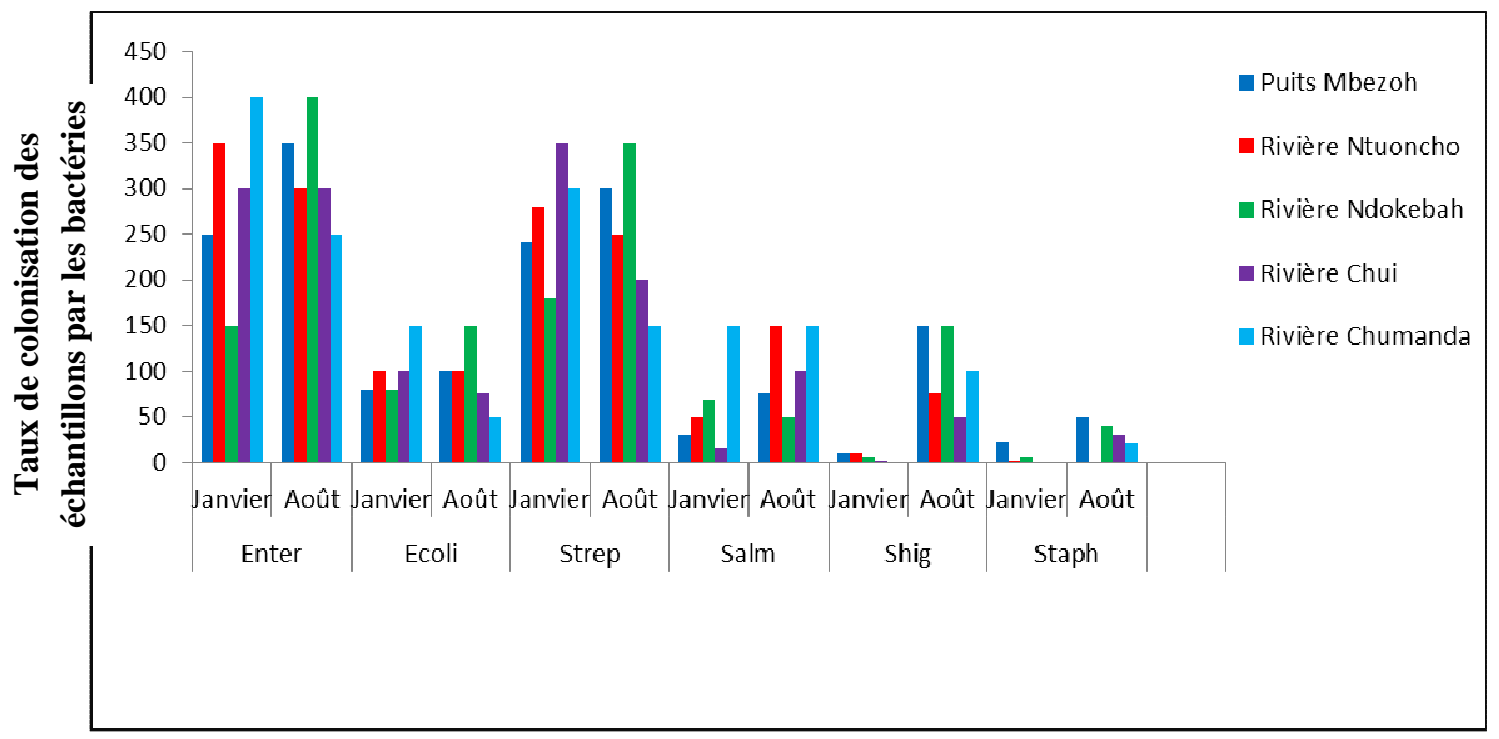

Figure 8 : Variation du taux de colonisation des échantillons par les bactéries.

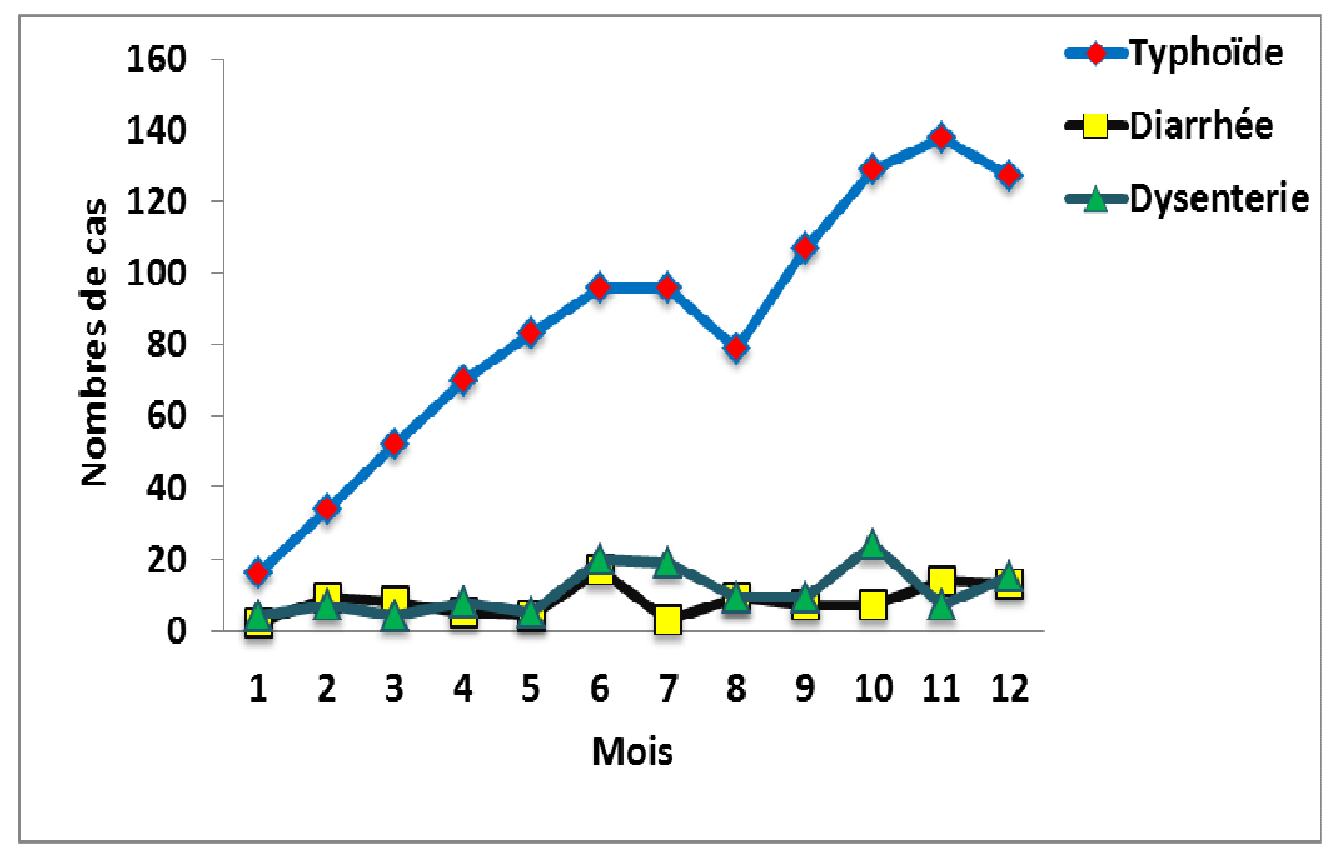

Figure 9: Distribution mensuelle des maladies d'origine hydrique enregistrées à Babessi entre janvier 2014 et décembre 2015. 


\section{N. E. B. TAMUNGANG et al /Int. J. Biol. Chem. Sci. 10(3): 1382-1402, 2016}

Tableau 1 : Paramètres physiques des sites de prelevement.

\begin{tabular}{|c|c|c|c|c|c|c|c|c|c|}
\hline \multirow[t]{2}{*}{ Quartiers } & \multirow[t]{2}{*}{ sites } & \multicolumn{2}{|c|}{$\mathbf{T}\left({ }^{\circ} \mathbf{C}\right)$} & \multicolumn{2}{|c|}{ pH } & \multicolumn{2}{|c|}{$\mathrm{CE}(\boldsymbol{\mu S} / \mathbf{c m})$} & \multicolumn{2}{|c|}{ Tu (NTU) } \\
\hline & & Janvier & Août & Janvier & Août & Janvier & Août & Janvier & Août \\
\hline Mbezoh & Puits & 20,7 & 22,1 & 6,3 & 5,5 & 111,0 & 280 & 9,9 & 33 \\
\hline Ntuoncho & Rivière & 19,8 & 21,8 & 6,6 & 5,7 & 152,2 & 68,9 & 20,3 & 163 \\
\hline Ndokebah & Rivière & 20 & 21,7 & 7,0 & 6,0 & 45 & 28,2 & 19 & 209 \\
\hline Chui & Rivière & 20 & 21,9 & 6,9 & 6,0 & 44 & 44,6 & 19,5 & 206 \\
\hline Chumanda & Rivière & 20,6 & 22,1 & 6,9 & 6,2 & 61,3 & 31,2 & 20,1 & 236 \\
\hline Normes OMS & & - & & $6,5-$ & 9,5 & $180-$ & 000 & 5 & \\
\hline
\end{tabular}

Tableau 2 : Teneur des eaux en ions majeurs.

\begin{tabular}{|c|c|c|c|c|c|c|c|c|c|c|c|c|c|c|c|c|c|c|c|c|c|}
\hline \multirow[t]{2}{*}{ Quartiers } & \multirow[t]{2}{*}{ Sites } & \multicolumn{2}{|c|}{$\mathrm{Ca}^{2+}(\mathrm{mg} / \mathrm{l})$} & \multicolumn{2}{|c|}{$\begin{array}{l}\mathrm{Mg}^{2+} \\
(\mathrm{mg} / \mathrm{l})\end{array}$} & \multicolumn{2}{|c|}{$\mathbf{K}^{+}(\mathrm{mg} / \mathrm{l})$} & \multicolumn{2}{|c|}{$\begin{array}{l}\mathrm{Na}^{+} \\
(\mathrm{mg} / \mathrm{l})\end{array}$} & \multicolumn{2}{|c|}{$\begin{array}{c}\mathrm{Cl}^{-} \\
(\mathrm{mg} / \mathrm{l})\end{array}$} & \multicolumn{2}{|c|}{$\begin{array}{l}\mathrm{SO}_{4}^{2-} \\
(\mathrm{mg} / \mathrm{l})\end{array}$} & \multicolumn{2}{|c|}{$\begin{array}{l}\mathrm{NO}_{3}^{-} \\
(\mathrm{mg} / \mathrm{l})\end{array}$} & \multicolumn{2}{|c|}{$\begin{array}{c}\mathrm{HCO}_{3}^{-} \\
(\mathrm{mg} / \mathrm{l})\end{array}$} & \multicolumn{2}{|c|}{$\begin{array}{l}\mathrm{PO}_{4}^{3-} \\
(\mathrm{mg} / \mathrm{l})\end{array}$} & \multicolumn{2}{|c|}{$\begin{array}{c}\mathrm{NH}_{4}^{+} \\
(\mathrm{mg} / \mathrm{l})\end{array}$} \\
\hline & & $\mathbf{J}$ & $\mathbf{A}$ & $\mathbf{J}$ & $\mathbf{A}$ & $\mathbf{J}$ & $\mathbf{A}$ & $\mathbf{J}$ & $\mathbf{A}$ & $\mathbf{J}$ & $\mathbf{A}$ & $\mathbf{J}$ & $\mathbf{A}$ & $\mathbf{J}$ & $\mathbf{A}$ & $\mathbf{J}$ & $\mathbf{A}$ & $\mathbf{J}$ & $\mathbf{A}$ & $\mathbf{J}$ & $\mathbf{A}$ \\
\hline Mbezoh & Puits & Traces & 48,67 & 0,57 & 4,04 & 0,26 & 11,03 & 0,03 & 1,31 & 88,75 & 3,25 & 0,19 & 1,80 & 0,168 & 3,64 & 97,6 & 109,8 & 3,41 & 0,001 & 0,084 & 1,12 \\
\hline Ntuoncho & Rivière & Traces & 47,00 & 0,81 & 4,04 & 0,11 & 11,84 & 0,03 & 2,72 & ND & ND & 0,15 & 2,10 & 0,112 & 1,96 & 134,2 & 58,56 & 8,52 & 0,001 & 0,252 & 3,92 \\
\hline Ndokebah & Rivière & Traces & 31,00 & 0,44 & 4,27 & 0,11 & 12,08 & 0,03 & 6,08 & ND & ND & 0,13 & 3,20 & 0,112 & 1,68 & 53,68 & 24,4 & 6,25 & 0.001 & 0,14 & 0,84 \\
\hline Chui & Rivière & Traces & 48,00 & 0,47 & 4,04 & 0,11 & 11,90 & 0,03 & 1,02 & ND & ND & 1,63 & 3,10 & 0,084 & 1,06 & 48,8 & 67,1 & 6,81 & 0,001 & 0,196 & 4,48 \\
\hline Chumanda & Rivière & Traces & 55,33 & 0,52 & 4,02 & 0,11 & 11,58 & 0,06 & 1,02 & ND & ND & 0,14 & 4,10 & 0,056 & 0,28 & 78,08 & 73,2 & 6,36 & 0,001 & 0,028 & 1,68 \\
\hline Normes OMS & & 25 & & 25 & & & & & & & & & & & & & & & & & \\
\hline
\end{tabular}

$\mathrm{J}=$ janvier ; A = août $; \mathrm{ND}=$ Non Détectable 
Tableau 3 : Teneur des eaux en metaux lourds.

\begin{tabular}{|c|c|c|c|c|c|c|c|c|c|}
\hline \multirow[t]{2}{*}{ Quartiers } & \multirow[t]{2}{*}{ Sites } & \multicolumn{2}{|c|}{$\mathrm{Cr}(\mathrm{mg} / \mathrm{l})$} & \multicolumn{2}{|c|}{$\mathrm{Fe}(\mathrm{mg} / \mathrm{l})$} & \multicolumn{2}{|c|}{$\mathbf{P b}(\mathrm{mg} / \mathrm{l})$} & \multicolumn{2}{|c|}{$\mathrm{Zn}(\mathrm{mg} / \mathrm{l})$} \\
\hline & & Janvier & Août & Janvier & Août & Janvier & Août & Janvier & Août \\
\hline Mbezoh & Puits & 0,14 & Traces & Traces & Traces & Traces & 0,08 & 0,83 & 0,29 \\
\hline Ntuoncho & Rivière & 0,16 & Traces & 0,26 & 0,07 & Traces & Traces & 1,2 & 0,23 \\
\hline Ndokebah & Rivière & 0,32 & 0,55 & 1,70 & Traces & Traces & 0,38 & 1,73 & 0,54 \\
\hline Chui & Rivière & 0,18 & Traces & 2,48 & 0,51 & Traces & Traces & 2,45 & 0,38 \\
\hline Chumanda & Rivière & 0,25 & Traces & 3,96 & Traces & Traces & Traces & 2,78 & 0,22 \\
\hline \multicolumn{2}{|c|}{ Normes OMS } & \multicolumn{2}{|c|}{0,05} & \multicolumn{2}{|c|}{0,3} & \multicolumn{2}{|c|}{0,01} & \multicolumn{2}{|c|}{3} \\
\hline
\end{tabular}

Tableau 4 : Nombre le plus probable de Coliformes fécaux dans les eaux échantillonnées.

\begin{tabular}{|c|c|c|c|c|c|}
\hline \multirow[b]{3}{*}{ Quartiers } & \multirow[b]{3}{*}{ Sites } & \multicolumn{4}{|c|}{$\begin{array}{l}\text { Nombre le plus probable de coliformes dans } 100 \mathrm{ml} \text { d'eau } \\
\text { initiale }\end{array}$} \\
\hline & & \multicolumn{2}{|c|}{ Moyenne } & \multicolumn{2}{|c|}{ Catégorie } \\
\hline & & Janvier & Août & Janvier & Août \\
\hline Mbezoh & Puits & 5 & 50 & $\mathrm{~B}$ & $\mathrm{D}$ \\
\hline Ntuoncho & Rivière & 12 & 20 & $\mathrm{C}$ & $\mathrm{C}$ \\
\hline Ndokebah & Rivière & 10 & 90 & $\mathrm{~B}$ & $\mathrm{D}$ \\
\hline Chui & Rivière & 90 & 14 & $\mathrm{D}$ & $\mathrm{C}$ \\
\hline Chumanda & Rivière & 35 & 18 & $\mathrm{D}$ & $\mathrm{C}$ \\
\hline
\end{tabular}

Tableau 5 : Microbes spécifiques isolés.

\begin{tabular}{|c|c|c|c|c|c|c|c|c|c|c|c|c|c|}
\hline \multirow[t]{2}{*}{ Quartiers } & \multirow[t]{2}{*}{ Sites } & \multicolumn{2}{|c|}{ Enter } & \multicolumn{2}{|c|}{ Ecoli } & \multicolumn{2}{|c|}{ Strep } & \multicolumn{2}{|c|}{ Salm } & \multicolumn{2}{|c|}{ Shig } & \multicolumn{2}{|c|}{ Staph } \\
\hline & & $\mathbf{J}$ & $\mathbf{A}$ & $\mathbf{J}$ & $\mathbf{A}$ & $\mathbf{J}$ & $\mathbf{A}$ & $\mathbf{J}$ & $\mathbf{A}$ & $\mathbf{J}$ & $\mathbf{A}$ & $\mathbf{J}$ & $\mathbf{A}$ \\
\hline Mbezoh & Puits & 250 & 350 & 80 & 100 & 240 & 300 & 30 & 75 & 10 & 150 & 22 & 50 \\
\hline Ntuoncho & Rivière & 350 & 300 & 100 & 100 & 280 & 250 & 50 & 150 & 10 & 75 & 02 & 00 \\
\hline Ndokebah & Rivière & 150 & 400 & 80 & 150 & 180 & 350 & 70 & 50 & 05 & 150 & 05 & 40 \\
\hline Chui & Rivière & 300 & 300 & 100 & 75 & 350 & 200 & 15 & 100 & 02 & 50 & 00 & 30 \\
\hline Chumanda & Rivière & 400 & 250 & 150 & 50 & 300 & 150 & 150 & 150 & 00 & 100 & 00 & 20 \\
\hline
\end{tabular}




\section{N. E. B. TAMUNGANG et al /Int. J. Biol. Chem. Sci. 10(3): 1382-1402, 2016}

Tableau 6: Coéfficients de corrélation (r) de Peason entre les paramètres $(\mathrm{n}=2)$.

\begin{tabular}{|c|c|c|c|c|c|c|c|c|c|c|c|c|c|}
\hline \multirow[t]{2}{*}{$\mathbf{J}$} & Paramètre & $\begin{array}{c}\mathrm{CE} \\
\mathrm{HCO}_{3}^{-}\end{array}$ & $\begin{array}{c}\mathrm{CE} \\
\mathrm{Mg}^{2+}\end{array}$ & $\begin{array}{c}\mathrm{Tu} \\
\mathrm{PO}_{4}^{3-}\end{array}$ & $\begin{array}{l}\mathrm{HCO}_{3}^{-} \\
\mathrm{Mg}^{2+}\end{array}$ & $\begin{array}{l}\mathrm{Cl}^{-} \\
\mathrm{K}^{+}\end{array}$ & $\begin{array}{c}\mathrm{Zn}^{2+} \\
\mathbf{F e}\end{array}$ & & & & & & \\
\hline & $\mathrm{r}$ & 0,981 & 0,901 & 0,901 & 0,959 & 1,000 & 0,977 & & & & & & \\
\hline \multirow[t]{2}{*}{$\mathbf{A}$} & Paramètre & $\begin{array}{c}\mathbf{p H} \\
\mathrm{NO}_{3}^{-}\end{array}$ & $\begin{array}{c}\mathrm{pH} \\
\mathrm{PO}_{4}^{3-}\end{array}$ & $\begin{array}{c}\mathrm{EC} \\
\mathrm{NO}_{3}^{-}\end{array}$ & $\mathrm{EC} \mathrm{Cl}{ }^{-}$ & $\begin{array}{c}\mathrm{Mg}^{2+} \\
\mathrm{Na}^{+}\end{array}$ & $\begin{array}{l}\mathrm{Mg}^{2+} \\
\mathrm{Pb}^{2+}\end{array}$ & $\begin{array}{l}\mathrm{Mg}^{2+} \\
\mathrm{Zn}^{2+}\end{array}$ & $\begin{array}{l}\mathrm{Mg}^{2+} \\
\mathrm{Cr}^{3+}\end{array}$ & $\begin{array}{l}\mathrm{Pb}^{2+} \\
\mathrm{Zn}^{2+}\end{array}$ & $\begin{array}{l}\mathrm{Pb}^{2+} \\
\mathrm{Cr}^{3+}\end{array}$ & $\begin{array}{l}\text { E. coli } \\
\text { Strept }\end{array}$ & $\begin{array}{l}\text { E. coli } \\
\text { Enter }\end{array}$ \\
\hline & $\mathrm{r}$ & $-0,949$ & $-0,921$ & 0,890 & 9,921 & 0,953 & 0,980 & 0,896 & 0,997 & 0,867 & 0,978 & 0,959 & 0,946 \\
\hline
\end{tabular}

Tableau 7 : Maladies d'origine hydrique enregistrées à Babessi de 2014 à 2015.

\begin{tabular}{|c|c|c|c|c|c|c|c|c|c|c|c|c|c|c|c|c|c|c|c|c|c|c|c|c|c|c|}
\hline \multirow[t]{2}{*}{ Maladies } & \multirow[t]{2}{*}{ Âge } & \multicolumn{10}{|c|}{ Mois (2014) } & \multicolumn{15}{|c|}{ Mois (2015) } \\
\hline & & 1 & 2 & 3 & 4 & 5 & 6 & 7 & 8 & 9 & 10 & 11 & 12 & 1 & 2 & 3 & 4 & 5 & 6 & 7 & 8 & 9 & 10 & 11 & 12 & Somme \\
\hline \multirow{2}{*}{$\begin{array}{l}\text { Typhoïde } \\
\text { (Salmonelle) }\end{array}$} & $0-10$ & 0 & 0 & & 4 & 1 & 2 & 0 & 5 & 5 & 9 & 9 & 2 & 6 & 1 & 19 & 19 & 35 & 44 & 29 & 16 & 17 & 22 & 22 & 18 & 285 \\
\hline & $>10$ & 0 & 0 & 2 & 7 & 4 & 7 & 4 & 19 & 16 & 33 & 29 & 35 & 10 & 33 & 31 & 40 & 43 & 43 & 63 & 39 & 69 & 65 & 78 & 72 & 742 \\
\hline \multirow[t]{2}{*}{ Diarrhée } & $0-10$ & 0 & 0 & 0 & 0 & 0 & 0 & 0 & 0 & 0 & 0 & 1 & 0 & 1 & 1 & 2 & 0 & 2 & 6 & 2 & 5 & 3 & 2 & 4 & 2 & 31 \\
\hline & $>10$ & 0 & 0 & 2 & 0 & 0 & 2 & 0 & 0 & 0 & 0 & 1 & 1 & 1 & 8 & 4 & 5 & 2 & 9 & 1 & 4 & 4 & 5 & 8 & 10 & 67 \\
\hline \multirow[t]{2}{*}{ Dysenterie } & $0-10$ & 0 & 0 & 0 & 0 & 0 & 0 & 0 & 1 & 0 & 0 & 0 & 1 & 3 & 6 & 1 & 4 & 2 & 16 & 13 & 6 & 2 & 5 & 2 & 7 & 69 \\
\hline & $>10$ & 1 & 0 & 0 & 0 & 0 & 0 & 0 & 0 & 0 & 0 & 0 & 0 & 0 & 1 & 3 & 4 & 3 & 4 & 6 & 2 & 7 & 19 & 5 & 7 & 62 \\
\hline
\end{tabular}

Sources : Centre de santé islamique intégré et centre médical de Babessi. 


\section{DISCUSSION}

Paramètres physiques

Les résultats du Tableau 1 affiche des valeurs de température relativement élevées et proche de la température ambiante $\left(25^{\circ} \mathrm{C}\right)$. La variation en température traduit l'influence de la saison ainsi que celle du climat du jour sur la qualité des eaux (Figure 2). L'OMS n'a recommandée aucune valeur pour la température de l'eau de boisson. Par contre, l'eau fraîche est généralement plus potable que l'eau chaude, et la température aura un impact sur l'acceptabilité d'un certain nombre d'autres constituants inorganiques et contaminants chimiques qui peuvent affecter le goût. La température élevée augmente la croissance des micro-organismes et peut augmenter des problèmes liés au goût, à l'odeur, à la couleur et à la corrosion (OMS, 2006).

Le $\mathrm{pH}$ de la plupart des points d'eau ne respectait pas la norme établie par l'OMS (6,5-8,5). Le $\mathrm{pH}$ mesure la concentration en ions $\mathrm{H}^{+}$de l'eau. Ce paramètre conditionne un grand nombre d'équilibres physicochimiques et dépend de facteurs multiples dont l'origine de l'eau (Aboudi et al., 2014). Ainsi la pluie (pluie acide) serait le principal facteur responsable de la diminution observée en août (Figure 2). Il a d'ailleurs été démontré qu'au $\mathrm{pH}$ acide, l'eau devient corrosive et peut endommager les équipements (Broo et al., 1997). Par conséquent, les faibles valeurs de $\mathrm{pH}$ affectent indirectement la santé humaine puisqu'elles favorisent la dissolution des métaux lourds qui peuvent avoir des conséquences défavorables sur des personnes (Sorlini et al., 2013). Les corrélations négatives entre $\mathrm{pH}$ et les paramètres tels que $\mathrm{NO}_{3}^{-}$et $\mathrm{PO}_{4}^{3-}$ montrent qu'une augmentation en $\mathrm{NO}_{3}^{-}$et $\mathrm{PO}_{4}^{3-}$ entraîne la diminution du $\mathrm{pH}$. La conductivité électrique des points d'eau était très faible comparée à la norme de l'OMS (180-1000 $\mu \mathrm{S} / \mathrm{cm})$ traduisant ainsi une faible minéralisation de ces derniers (Figure 2). Les fortes corrélations positives entre $\mathrm{CE}$ et les paramètres tels que $\mathrm{HCO}_{3}^{-}, \mathrm{Mg}^{2+}$,
$\mathrm{NO}_{3}^{-}$et $\mathrm{Cl}^{-}$peuvent s'expliquer par le fait que $\mathrm{CE}$ traduit la capacité d'une solution à conduire le courant électrique, ceci étant réalisé par ces porteurs de charge. Les résultats similaires de température, $\mathrm{pH}$ et conductivité électrique ont été également signalés par Wirmvem et al. (2013a) dans les eaux souterraines peu profondes et eau de surface dans la plaine de Ndop. Les valeurs de la turbidité enregistrées étaient largement supérieures à la limite (5 NTU) prescrite par l'OMS avec une augmentation considérable au mois d'août comme le montre la Figure 2. Cette forte turbidité était sûrement due à la présence des matières en suspension finement divisées telles que les argiles et les limons (WHO, 2011). Il est à noter qu'une forte turbidité peut favoriser la prolifération des micro-organismes qui peuvent se fixer sur les particules en suspension ayant un effet protecteur de ces micro-organismes contre la désinfection (WHO, 2011; Gnazou et al., 2015). Ainsi, ces eaux étaient toutes troubles et leur qualité bactériologique était donc suspecte. La filtration avant consommation était donc nécessaire. Cette observation a été partagée par Temgoua (2011) lorsqu'il analysait les eaux de boisson de différentes sources dans la municipalité de Dschang, Cameroun. L'augmentation considérable observée au mois d'août serait due à l'action des eaux de ruissellement.

\section{Paramètres chimiques}

Tous les ions majeurs étaient en dessous des valeurs guides établies par l'OMS (Tableaux 2 et 3 ). Les faibles teneurs en Calcium et Magnésium, indice de la dureté, indiquaient les eaux douces (Lagnika et al., 2014) (Figure 3). Ces résultats sont en accord avec ceux de Wirmvem et al. (2013a) et Ghazali et Zaid (2013). Bien que les études épidémiologiques montrent un effet protecteur de dureté sur la mortalité cardiovasculaire, l'évidence est discutée et ne prouve pas la causalité. Les études approfondies sont encore en cours et les données actuelles sont 
insuffisantes pour suggérer les concentrations minimales ou maximales, étant donné que la teneur consommée dépendra d'une gamme d'autres facteurs (WHO, 2011 ; Salvadogo et al., 2013). Les faibles teneurs en ion $\mathrm{K}^{+}$ étaient probablement dues à leur faible mobilité géochimique (Wirmvem et al., 2013a). En plus, le potassium est rarement rencontré dans l'eau à des concentrations pouvant porter atteinte à la santé et sa dose quotidienne s'élève à plus de 3000 mg (WHO, 2011), raison pour laquelle aucune valeur guide n'a été établie pour ce dernier. Les concentrations en $\mathrm{Na}^{+}$variaient entre 0,03 et $6,08 \mathrm{mg} / \mathrm{l}$ qui étaient d'ailleurs très faibles comparées à la valeur guide de $50 \mathrm{mg} / \mathrm{l}$ établie par l'OMS. Néanmoins, sa présence pourrait être attribuée à la lixiviation des formations géologiques contenant du chlorure de sodium ainsi que de la décomposition de sels minéraux comme les silicates de sodium et d'aluminium (Belgiti et al., 2013). Il est impliqué à long terme parmi les facteurs favorisant la genèse d'une hypertension artérielle (Botta et Bellon, 2004). Les très faibles teneurs observées qui sont d'ailleurs très proches de celles obtenues par Belghiti et al (2013) dans les eaux souterraines de la nappe plio-quaternaire dans la région de Meknès au Maroc, seraient dues à la nature du sol ainsi que la localisation géographique de la zone d'étude. Les concentrations en ion $\mathrm{NH}_{4}^{+}$ étaient très faibles (Figure 3) comparées à 35 $\mathrm{mg} / \mathrm{l}$ établie par l'OMS. L'ammonium constitue le produit de la réduction finale des substances organiques azotées et de la matière inorganique dans les eaux et les sols. Il provient également de l'excrétion des organismes vivants et de la réduction et la biodégradation des déchets, sans toutefois négliger les apports d'origine domestique, agricole et industrielle (Aboudi et al., 2014).

Sa présence dans l'eau est un indicateur de pollution bactérienne possible, d'eaux d'égout, et de déchets des animaux (WHO, 2011).
Les ions $\mathrm{Cl}^{-}$n'étaient présents que dans le puits du quartier Mbezoh et à de très faibles concentrations comparées à la norme de $250 \mathrm{ml}$ (Figure 4). Il a été montré que les eaux trop riches en $\mathrm{Cl}^{-}$sont laxatives et corrosives. Par contre, la concentration en cet ion dépend fortement de la nature du sol (Belghiti et al., 2013). Les ions $5 \mathbf{S O}_{4}^{2-}$ avait une concentration minimale de $0,13 \mathrm{mg} / 1$ dans la rivière du quartier Ndokebah et une concentration maximale de 4,10 mg/l dans la rivière du quartier Chumanda pendant l'étude. Mais, aucune valeur directive n'a été établie pour ces derniers. Cependant, en raison des effets gastro intestinaux pouvant résulter de l'ingestion de l'eau contenant des fortes concentrations, il est recommandé que les services d'hygiène soient avisés des sources de l'eau potable qui contiennent des concentrations en sulfate au-dessus de 500 mg/l (WHO, 2011). Il faut de même noter que la présence de ces ions sulfates peut être due à l'eau de pluie (pluies acides), la mise en solution de roches sédimentaires évaporitiques, l'utilisation d'engrais chimique et la lessive (Aboudi et al., 2014). Les concentrations en $\mathrm{NO}_{3}^{-}$variaient entre 0,056 et $3,46 \mathrm{mg} / \mathrm{l}$. Ces faibles concentrations enregistrées comparées à la norme de 50 mg/l de l'OMS suggèrent la sorption de $\mathrm{NO}_{3}^{-}$par la matière organique dans la zone sous-saturée (Wirmvem et al., 2013a). Ces faibles concentrations pouvaient également être dues à la croissance d'algues des eaux d'égout (Orjiekwe et al., 2013). $\mathbf{N O}_{3}^{-}$provient naturellement du sol mais il est aussi apporté de manière synthétique par les engrais. Sur le plan sanitaire, le risque majeur associé à $\mathrm{NO}_{3}^{-}$ est la méthémoglobinémie encore appelée maladie du bébé bleu résultant du mauvais tranfert de l'oxygène par le sang causée par les nitrites provenant de la transformation des nitrates par l'organisme (Ghazali et Zaid, 2013). Les concentrations en $\mathrm{HCO}_{3}^{-}$indice de l'alcalinté variait entre 24,4 et $134,2 \mathrm{mg} / \mathrm{l}$. Les 
analyses ont confirmé l'absence des ions carbonates et hydroxyles. Les valeurs acceptables de l'alcalinité sont $200 \mathrm{mg} / \mathrm{l}$ et une eau de forte alcalinité a un mauvais goût (Temgoua, 2011). Ces concentrations en $\mathrm{HCO}_{3}^{-}$qui n'excédaient pas la limite traduisaient de même la dominance de ces ions dans les différents points d'eau (Figure 4). Cela serait dû à l'attaque des minerais de silicate dans le sol de la zone d'étude par le $\mathrm{CO}_{2}$ dissout (Wirmvem et al., 2013a). Les teneurs en $\mathrm{PO}_{4}^{3-}$ variaient entre 0,001 et 8,25 $\mathrm{mg} / \mathrm{l}$ (Figure 4). Aucune directive n'a été établie pour ce dernier. Cependant, à des teneurs trop élevées, $\mathrm{PO}_{4}^{3-}$ est susceptible de favoriser la multiplication des algues dans les réservoirs, les canalisations de grand diamètre, les eaux de lacs et de rivières contribuant ainsi à l'eutrophisation du milieu (Ladjel, 2009).

La composition métallique des eaux étudiées était très variable. Les concentrations en Zinc respectaient la norme (3 mg/l). Par contre, les concentrations en Plomb, Chrome et Fer étaient largement supérieures aux normes $(0,01 \mathrm{mg} / \mathrm{l}, 0,05 \mathrm{mg} / \mathrm{L}$ et $0,3 \mathrm{mg} / \mathrm{L}$ respectivement). La présence de ces métaux était sûrement liée à la nature du sol étant donné que l'activité industrielle est très réduite dans la zone d'étude. Les différences significatives notées dans la variation de $\mathrm{Mg}^{2+}, \mathrm{K}^{+}, \mathrm{SO}_{4}^{2-} \mathrm{NO}_{3}^{-}, \mathrm{PO}_{4}^{3-}, \mathrm{NH}_{4}^{+}$et $\mathrm{Zn}^{2+}$ en janvier et août traduisent l'influence des saisons sur la qualité de l'eau. Ces variations étaient probablement dues à la double action (dissolution des formations rocheuses et dilution) de la pluie au mois d'août. Les corrélations positives entre $\mathrm{HCO}_{\Xi}^{-}$ et $\mathrm{Mg}^{2+} ; \mathrm{Cl}^{-}$et $\mathrm{K}^{+} ; \mathrm{Zn}^{2+}$ et $\mathrm{Fe}$; $\mathrm{Mg}^{2+}$ et $\mathrm{Cr}^{3+} ; \mathrm{Mg}^{2+}$ et $\mathrm{Na}^{+} ; \mathrm{Mg}^{2+}$ et $\mathrm{Pb}^{2+} ; \mathrm{Mg}^{2+}$ et $\mathrm{Zn}^{2+} ; \mathrm{Na}^{+}$et $\mathrm{Pb}^{2+}$; $\mathrm{Na}^{+}$et $\mathrm{Cr}^{3+} ; \mathbf{P b}^{2+}$ et $\mathrm{Zn}^{2+} ; \mathrm{Pb}^{2+}$ et $\mathrm{Cr}^{{ }^{3+}}$ (Tableau 6) suggèrent l'origine commune de ses ions (Wotany et al., 2013).
Le diagramme de Pipers (Figure 6), démontre les différents types d'ions dans les échantillons d'eau (Piper, 1953). Le graphe des données chimiques sur le diagramme trilinear de Piper révèle que la majorité des échantillons d'eau se trouve dans les facies de $\mathrm{Na}^{+}, \mathrm{K}^{+}, \mathrm{Ca}^{2+}, \mathrm{Mg}^{2+}$ et $\mathrm{CO}_{3}{ }^{2-}, \mathrm{HCO}_{3}^{--}$.

\section{Paramètres bactériologiques}

Les eaux étudiées contenaient des taux élevés de coliformes fécaux (Figure 7). Les analyses approfondies ont également permis d'isoler des enterobacterères, Escherichia coli, streptocoques, salmonelles, shigelles et staphylocoques ce qui suggérait la présence possible d'autres microbes comme les virus et protozoaires. En dehors des Shigelles et Staphilocoques qui variaient significativement, le taux de colonisation des points par les autres bactéries était constant, les entérobactères et les streptocoques étant les plus abondants (Figure 8).Wirmvem et al. (2013b) avaient également signalé une forte présence des coliformes dans les eaux souterraines peu profondes de la plaine de Ndop. La mauvaise qualité de ces eaux pouvait s'expliquer non seulement par le manque d'hygiène mais aussi par le mauvais assainissement (Davis et Hirji, 2003 ; Nanfack et al., 2013). La plupart des points d'eau consommés sont localisés dans des endroits avec un taux de pollution élevée provenant des latrines, des poubelles, des fermes d'élevages et des exploitations agricoles. Ceci implique qu'ils subissent une infiltration des microorganismes pathogènes provenant des latrines. De même, les eaux de ruissellements seraient d'une part responsables de la présence des bactéries dans ces eaux (Geldreich, 1998). Les corrélations positives entre Escherichia coli et streptocoques; Escherichia coli et enterobactères (Tableau 6) indiquent les origines communes de ces derniers. Les points d'eau sont souvent visités par les animaux assoiffés qui boivent et partagent la même eau avec des humains. Ces animaux défèquent dans ces points d'eau polluant ainsi davantage les eaux. En plus de 
ces multiples constats, s'ajoute le comportement navrant de certains adultes qui mènent des actions à forts impacts pathologiques telles que le lessivage autour de certaines sources. Djuikom et al. (2011) ont fait le même constat lorsqu'ils étudiaient la qualité de l'eau dans les puits du quartier Bépanda à Douala. De même, Nanfack et al. (2013), dans leur étude sur les eaux non conventionnelles: un risque ou une solution aux problemes d'eau pour les classes pauvres de la ville de Mbouda, sont parvenus à la même conclusion.

\section{Convenance des eaux à la consommation humaine et effets sanitaires}

Les valeurs de $\mathrm{pH}$ inférieures à la norme $(6,5)$ établie par l'OMS montraient le caractère corrosif de ces eaux. Les fortes turbidités posaient d'énormes problèmes sur l'acceptabilité ainsi que la qualité microbiologique des eaux (WHO, 2011). Les eaux étaient douces, étant donné les faibles concentrations en ions $\mathrm{Ca}^{2+}$ et $\mathrm{Mg}^{2+}$. En plus, les ions $\mathrm{Ca}^{2+}$ étaient quasi absents en janvier. Ces concentrations étaient inférieures à la limite requise c'est-à-dire $10 \mathrm{mg} / \mathrm{l}$ pour $\mathrm{Ca}^{2+}$ et $20 \mathrm{mg} / 1$ pour $\mathrm{Mg}^{2+}$. Ainsi, la douceur générale de ces eaux pourrait être un problème de santé puisque l'eau douce a été liée aux maux cardiovasculaires (Kozisek, 2005 ; Wirmvem et al., 2013a). Les fortes concentrations du Plomb, Chrome et Fer dans la plupart des points d'eau représentaient un risque sanitaire important pour la population. Le Plomb est reconnu comme un toxique cumulatif, thioloprive, neurotoxique, néphrotoxique et hématotoxique, responsable $\mathrm{du}$ saturnisme hydrique ayant des conséquences redoutables chez les enfants (Botta et Bellon, 2004). Les dérivés hexavalents du Chrome sont potentiellement cancérogènes et sont donc très préoccupants pour la santé humaine (Botta et Bellon, 2004). Quant au Fer, il confère une saveur désagréable à l'eau à partir de $0,05 \mathrm{mg} / \mathrm{l}$, développe une turbidité rougeâtre peu engageante pour le consommateur et favorise la prolifération bactérienne dans l'eau (Botta et Bellon, 2004 ; WHO, 2011). Du point de vue bactériologique, aucun des points d'eau ne respectait les normes. La présence des coliformes fécaux dans ces eaux ou d'autres agents pathogenès liés à la pollution fécale ou issue d'autres origines est dangereuse pour la santé (OMS, 2004 ; Temgoua et al., 2009). La consommation de ces eaux expose la population de cette localité à de nombreuses maladies d'origine hydrique telles que la typhoïde, la dysenterie, la miningite et la diarrhée, étant donné que ces eaux contiennent des taux élevés d'enterobacterères, de Escherichia coli, de streptocoques, de salmonelles, de shigelles et de staphylocoques (WHO, 2011). La mauvaise qualité microbienne des points d'eau était justifiée par la prédominance des maladies d'origine hydrique dans la zone d'étude presentée dans le Tableau 7. Ce tableau regroupe les cas de maladies d'origine hydrique enregistrées dans deux centres de santé dans le village Babessi de 2014 à 2015. Les résultats du Tableau 7 montrent la présence dans les différents points d'eau des pathogènes intestinaux responsables de la thyphoïde, de la diarrhée et de la dysenterie, la thyphoïde étant la plus répendue. On constate que la thyphoïde et la diarrhée affectent plus les personnes dont les âges sont supérieur à 10 ans alors que la dysenterie est presque équilibrée entre les tranches d'âge. Cette observation contraste avec celle de Wirmvem et al. (2013b). Il faut noter que ces résultats ne représentent que quelques cas parmi tant d'autres étant donné que dans la plupart des milieux ruraux du Cameroun, la population fait plus confiance à la médecine traditionnelle qu'à la médecine moderne dans le traitement des infections d'origine hydrique.

La distribution mensuelle des maladies d'origine hydrique enregistrées à Babessi entre janvier 2014 et décembre 2015 est présentée par la Figure 9. La forte présence des infections d'origine hydrique entre mars et juillet peut être due à la rentrée de la pluie 
ainsi que les fortes pluies qui auraient entraîné les bactéries dans les différentes sources d'eau. Le départ de la pluie entre octobre et novembre serait responsable de la concentration des bactéries dans les sources d'eau, augmentant ainsi les infections observées en ces mois. Ce cycle résulte en l'occurrence des infections d'origine hydrique tout au long de l'année.

\section{Conclusion}

A l'issue des analyses physiques, chimiques et bactériologiques effectuées sur les eaux domestiques dans les village Babessi, Nord-Ouest Cameroun, il est à noter que sur l'aspect physique, le $\mathrm{pH}$ légèrement acide et la forte turbidité étaient les principaux paramètres qui rendaient les eaux inacceptables pour la consommation. En ce qui concerne les paramètres chimiques, tous les ions majeurs étaient présents à de faibles concentrations et ne posaient donc aucun risque de pollution. Concernant les métaux lourds, la présence du plomb, chrome et fer est très préoccupante étant donné qu'ils sont responsables du saturnisme hydrique, du cancer d'une saveur désagréable et de la prolifération bactérienne dans l'eau. Les analyses bactériologiques ont révélé la présence dans tous les points d'eau, des coliformes fécaux indice de la pollution fécale ainsi que d'autres bactéries pathogènes (Entérobactères, Escherichia coli, streptocoques, salmonelles, shigelles et staphylocoques) qui sont responsables de la typhoïde, la dysenterie et les gastroentérites, les entérobactères et Streptococcus étant les plus abondants. Les analyses statistiques ont d'ailleurs révélé une différence significative dans la variation de certains paramètres pendant les deux saisons ainsi que des fortes corrélations entre différents paramètres aussi bien en janvier qu'en août.

Dans l'ensemble, les eaux dont s'approvisionne la population de Babessi pour les usages domestiques ne respectent pas les normes de qualités recommandées par l'OMS. La mauvaise qualité de ces eaux était justifiée par la prédominance des infections d'origine hydrique dans ce village notamment la thyphoïde, la diarrhée et la dysenterie. Pour palier à cela, la population devrait être sensibilisée sur les risques sanitaires liés à la consommation de ces eaux. Elle devrait également être éduquée sur les méthodes de traitement de l'eau de boisson à domicile, à l'instar de la filtration, l'utilisation de l'eau de javel et la désinfection solaire de même que sur les risques de pollution liées au mauvais entretien, à la mauvaise utilisation des produits chimiques en agriculture et à un mauvais assainissement. Enfin, les analyses organoleptiques, physiques, chimiques et bactériologiques devraient être périodiquement effectuées sur ces eaux afin d'identifier les différentes sources précises de pollution.

\section{CONFLIT D'INTERETS}

Les auteurs déclarent qu'ils n'ont aucun conflit d'intérêts.

\section{CONTRIBUTIONS DES AUTEURS}

NEBT a supervisé les travaux de recherche à tous les stades et NFB a effectué les travaux sur le terrain et en laboratoire, a analysé les données et assemblé le manuscrit. MNA a aidé à superviser les travaux de recherche tandis que DYT a dirigé et édité le manuscrit.

\section{REMERCIEMENTS}

Nous tenons à remercier les indigènes de la communauté Babessi pour nous avoir permis de prélever des échantillons de leurs cours d'eau pour cette étude; le chef et les techniciens de LAASCE et LAPAM , FASA et LACHINGE, FS pour nous avoir aidé dans l'analyse des échantillons.

\section{REFFERENCES}

Abboudi A, Tabyaoui H, El Hamichi F, Benaabidate L, Lahrach A. 2014. Etude de la qualité physico-chimique et contamination métallique des eaux de surface du bassin versant de Guigou, 
Maroc. European Scientific Journal, 10: 1857 - 7881 .

Belghiti ML, Chahlaoui A, Bengoumi D, El Moustaine R. 2013. Etude de la qualité physico-chimique et Bactériologique des eaux souterraines de la nappe plioquaternaire dans la région de meknès (Maroc). Larhyss Journal., 14: 21-36.

Botta A, Bellon L. 2004. Pollution Chimique de l'Eau et Santé Humaine. Support de formation, Université d'Aix-Marseille, Marseille, France.

Broo AE, Berghult B, Hedberg T. 1997. Copper corrosion in drinking water distribution systems-the influence of water quality. Corrosion Science, 39: 1119-1132.

CAMAAY. 2015. Study on Water Management in Four Villages of Babessi Municipality. Cameroon Association of Active Youths.

CVUC. 2014. Commune de Babessi. Communes et villes unies du Cameroun.

Davis R, Hirji R. 2003. Water Quality: Assessment and Protection. Water Resources and Environment Technical Note D.1. The World Bank: Washington, D.C, Washington, United States of America.

Djuikom E, Jugnia LB, Nola M. 2011. Assessment of the quality of water in wells at Bépanda quarter, DoualaCameroon, by use of the indicator bacteria of faecal contamination. Journal of Applied Bioscience, 37: 2434 - 2440.

Fonteh MF. 2003. Water for People and Environment : The United Nations Cameroon water development Report. United Nations Economic Commission for Africa, Addis Abeba, Ethiopia.

Geldreich EE. 1998. The Bacteriology of Water. Tosaley and Wilson's Microbiology and Microbial Infection (9th edn). Arnold Pub.: London.

Ghazali D, Zaid A. 2013. Etude de la qualité physico-chimique et bactériologique des eaux de la source ain Salama-Jerri (région de Meknes -Maroc). Larhyss Journal, 12: 25-36.

Gnazou MDT, Assogba K,Sabi BE, Bawa LM. 2015. Qualité physico-chimique et bactériologique des eaux utilisées dans les écoles de la préfecture de Zio (Togo). Int. J. Biol. Chem. Sci., 9(1): 504-516. doi : http://dx.doi.org/10.4314/ ijbcs.v9i1.43

Hounsou MB, Agbossou EK, Ahamide B, Akponikpe I. 2010. Qualité bactériologique de l'eau du bassin de l'Ouémé: cas des coliformes totaux et fécaux dans les retenues d'eau de l'Okpara, de Djougou et de Savalou au Bénin., Int. J. Biol. Chem. Sci., 4(2): 377-390. doi : http://dx.doi.org/10.4314/ ijbcs.v4i2.58128

Kozisek F. 2005. Health Risks from Drinking Demineralised water. In: Nutrients in Drinking Water. World Health Organization: Geneva, Suizerland; 148-163.

Labas J, Vuik R. 2010. Forage à la Tarière Manuelle. Manuel de Formation Technique. Fondation PRACTICA.

Ladjel S. 2009. Contrôle des Paramètres Physico-Chimiques et Bactériologiques d'une Eau de Consommation. Les Cahiers Techniques du Stage. Centre de formation en métiers de l'eau: Tizi Ouzou.

Lagnika M, Ibikounle M, Montcho JPC, Wotto VD, Sakiti NG. 2014. Caractéristiques physico-chimiques de l'eau des puits dans la commune de Pobè (Bénin, Afrique de l'ouest). Journal of Applied Biosciences, 79: 6887 - 6897.

N'diaye A. 2008. Etude bactériologique des eaux de boissons vendues en sachet dans quatre communes d'Abidjan. Thèse de Doctorat, Université de Bamako, Bamako, Mali, p.166.

Nanfack NAC, Fonteh FA, Payne VK, Katte B, Fogoh JM. 2014. Eaux non conventionnelles: un risque ou une solution aux problèmes d'eau pour les 
classes pauvres. Larhyss Journal, 17: 47-64.

OMS, UNICEF. 2015. Rapport 2015 du JMP : faits essentiels. Programme commun Organisation mondiale de la santé /Fonds des nations unies pour l'enfance de suivi de l'approvisionnement en eau et de l'assainissement.

OMS. 1994. Directives de Qualite pour l'Eau de Boisson (2ème edn). Organisation mondiale de la santé : Genève, Suisse.

OMS. 2004. Directives de Qualite pour l'Eau de Boisson (3ème edn). Organisation Mondiale de la Santé : Genève, Suisse.

OMS. 2006. Water and Sanitation Related Diseases Fact. Organisation Mondiale de la Santé : Genève, Suisse.

Orjiekwe CL, Dumo DT, Chinedu NB. 2013. Assessment of water quality of Ogbese River in Ovia North-East LocalGovernment Area of Edo State, Nigeria. Int. J. Biol. Chem. Sci., 7(6): 2581-2590. doi: http://dx.doi.org/ 10.4314/ijbcs.v7i6.32

Piper AM. 1953. A graphic procedure in the geochemical interpretation of water analyses. Trans. U.S. Geol. Surv. Groundwater Notes 12.

Rodier JJ, Beuffe H, Bournaud M, Broutin JP, Geoffray C, Kovacsik G, Laporte J, Pattee E, Plissier M, Rodi L, Vial J. 1984. Analyse de l'Eau (7ème édn). DUNOD: Paris, France.

Savadogo B, Kaboré A, Zongo D, Poda JN, Bado H, Rosillon F, Dayeri D. 2013. Problematic of drinking water access in rural area: case study of the Sourou valley in Burkina Faso. Journal of Environmental Protection, 4: 31-50. doi:10.4236/jep.2013.41004

Sorlini S, Palazzini D, Sieliechi JM, Ngassoum MB. 2013. Assessment of Physical-Chemical Drinking Water Quality in the Logone Valley (ChadCameroon). Sustainability, 5: 30603076. doi:10.3390/su5073060
Temgoua E, Ngnikam E, Ndongson B. 2009. Drinking water quality: stakes of control and sanitation in the town of Dschang Cameroon., Int. J. Biol. Chem. Sci., 3(3): 441-447: doi : http://dx.doi.org/ 10.4314/ijbcs.v3i3.45346

Temgoua E. 2011. Chemical and Bacteriological Analysis of Drinking Water from Alternative Sources in the Dschang Municipality, Cameroon. Journal of Environmental Protection, 2: 620-628. doi:10.4236/jep.2011.25071.

Torkil JC. 2004. Integrated Water Resources Management (IWRM) and Water Efficiency plans by Why, What and How? Global Water Partnership.

WHO. 2011. Guidelines for Drinking Water Quality $\left(4^{\text {th }}\right.$ edn). World Health Organization: Geneva, Switzerland.

Wirmvem MJ, Fantong WY, Wotany E R, Takeshi O, Ayonghe SN. 2013b. Sources of bacteriological contamination of shallow groundwater and health effects in Ndop plain, Northwest Cameroon. Journal of Environmental Science and Water Resources, 2: 127 - 132.

Wirmvem MJ, Takeshi O, Fantong WY, Ayonghe SN, Suila JY, Asobo NEA, Tanyileke G, Joseph VH. 2013a. Hydrochemistry of shallow groundwater and surface water in the Ndop plain, North West Cameroon. African Journal of Environmental Science and Technology, 7: 518-530.

Wotany ER, Ayonghe SN, Fantong WY, Wirmvem MJ, Takeshi O. 2013. Hydrogeochemical and anthropogenic influence on the quality of water sources in the Rio del Rey Basin, South Western, Cameroon, Gulf of Guinea. African Journal of Environmental Science and Technology, 7 : 1053-106. DOI: 10.5897/AJEST2013.157 